\title{
La actividad turística en el litoral de la Región de Murcia (Sureste de España): breves consideraciones sobre su evolución reciente y estado actual
}

\author{
Rubén Giménez García* Daniel Moreno Muñoz** \\ Ramón García Marín**** \\ Universidad de Murcia (España)
}

\begin{abstract}
Resumen: La fachada mediterránea ha constituido, históricamente, un espacio de referencia turística a escala nacional e internacional. Entre las delimitaciones administrativas localizadas en esta franja litoral, la Región de Murcia ha quedado estancada respecto al resto. Este estudio pretende analizar el proceso, evolución y causas que han llevado a esta región a quedar descolgada del desarrollo turístico llevado a cabo por las comunidades y provincias litorales mediterráneas. Asimismo, se analiza el contraste entre las diferentes áreas turísticas regionales, intentando conocer los espacios de mayor pujanza y las razones que han llevado a dicha situación. La metodología empleada es de tipo cuantitativa, utilizando los datos estadísticos oficiales aportados por la Comunidad Autónoma de la Región de Murcia y el Instituto Nacional de Estadística (INE). Los principales resultados de la investigación evidencian el atraso turístico de la Región de Murcia, así como las dilatadas desigualdades existentes entre los municipios costeros que la integran.
\end{abstract}

Palabras Clave: Murcia; Turismo; Litoral; Hotel; Viajero.

Tourist activity on the coast of the Region of Murcia (Southeast of Spain): brief considerations on its recent evolution and current state

Abstract: The Mediterranean coastal front has traditionally been a focus of tourism on a national and international scale. With regards to the administrative delimitations of the coastline, the situation in the Region of Murcia has been long stagnant, resulting in slower and more unequal processes of modernisation than in other similar regions of Spain. This study is directed at analysing the processes, evolution and causes for this relative divorce between Murcia and the rest of the Mediterranean coastal communities and provinces. A comparison and contrast is made of the various different regional tourist areas in an attempt to ascertain areas of greater strength and the reasons that have led to these being so. The methodology used is quantitative, using the official statistics provided by the Autonomous Community of the Region of Murcia and the National Institute of Statistics. The main results of this research underline how the Region of Murcia lags behind the rest in terms of tourism, as well as the broad-ranging inequalities existing between the Murcian coastal municipalities.

Keywords: Murcia; Tourism; Coastline; Hotel; Traveller.

\section{Introducción}

A mediados del siglo XX el turismo comenzó a constituir un fenómeno de masas en la mayor parte de países desarrollados (Sebit et al., 2016). El incesante progreso de este fenómeno ha incentivado su consideración como uno de los sectores de mayor crecimiento a escala global (Navarro et al., 2015). En España, la actividad turística es un motor económico de elevada relevancia, conformando el segmento que mejor se ha adaptado a las diferentes situaciones atravesadas por el país (Artal et al., 2010). La capacidad de autorrenovación de este sector ha provocado que cobre elevado valor en el proceso de modernización y desarrollo experimentado

\footnotetext{
* Universidad de Murcia (España); E-mail: ruben.gimenez@um.es; https://orcid.org/0000-0001-7889-994X

* Universidad de Murcia (España); E-mail: daniel.moreno1@um.es; https://orcid.org/0000-0003-2264-263X

*** Universidad de Murcia (España); E-mail: ramongm@um.es; https://orcid.org/0000-0003-3268-5182
} 
por la economía española (Serrano y Calmés, 1998). La actividad turística en España representó el 15\% del Producto Interior Bruto en 2019, muestra inequívoca de que es una de las expresiones más evidentes de la actual sociedad de consumo y un gran estimulador en el gasto de otros bienes y servicios derivados de la misma, lo que provoca una evidente dinamización económica (Giménez et al., 2018a).

Desde la década de 1960, España asiste a un proceso de desarrollo turístico constante. El avance de este fenómeno viene impulsado por la conjunción de diversos factores: la apertura del país hacia el exterior, la posibilidad que tienen los ciudadanos de algunos países europeos de disfrutar de vacaciones pagadas, la mejora en los medios de transporte que permiten una mayor movilidad, o la bonaza climática, entre otros. La correcta combinación de todo ello se traduce en el afianzamiento del turismo como una de las fórmulas que, en cierto modo, rigen el progreso y evolución del país (Pack, 2009).

Debido a su tradicional condición recreativa y de ocio, las áreas litorales son los espacios en los que esta actividad se manifiesta de forma más evidente (Blázquez e Yrigoy, 2016). Entre las diferentes franjas costeras, la fachada mediterránea ostenta el mayor desarrollo nacional (Serrano, 2007). Se trata de una zona en la cual prima un modelo turístico de sol y playa definido por el predominio de una demanda masiva de individuos de clase media que, en gran medida, se alojan en establecimientos hoteleros de la misma categoría (Vera, 1994). Para satisfacer tal necesidad hospedera, gran parte de las áreas litorales españolas se vieron inmersas en un proceso urbanizador que proporcionó las infraestructuras necesarias para consolidar este fenómeno social. En este sentido, la industria turística forzó un escenario inmobiliario en el cual comenzaron a brotar edificaciones de distinta tipología (hoteles, apartamentos, resort, adosados, etc.) (Moreno, 2007). Las mayor parte de viviendas construidas son ocupadas, preferentemente, de forma estacional (Goulding et al., 2004), incentivando un dilatado contraste demográfico entre el periodo estival y el resto del año (Huete, 2008).

El clima y las playas constituyen el principal reclamo de estas áreas, provocando que la afluencia de turistas no cese año tras año (Espejo, 2011). Ahora bien, no todos los destinos turísticos litorales poseen la misma relevancia. Actualmente, se pueden apreciar diversas discrepancias en el desarrollo turístico de las diferentes delimitaciones administrativas que componen la franja costera mediterránea (Aledo, 2016). Sin embargo, ciertos emplazamientos están siendo afectados por el proceso de agotamiento expuesto y analizado por Butler (1980), bajo la denominación de "ciclo de vida de destinos turísticos". Esta teoría identifica las causas que llevan a la pérdida de atractivo, posterior estancamiento y declive turístico de los espacios de ocio y recreación (Heitmann, 2011). Para evitar el surgimiento de este fenómeno, las localidades costeras españolas tantean, durante los últimos años, estrategias de diferenciación, ideando nuevos productos turísticos que incrementen la singularidad de los destinos, evitando, en cierto modo, la masificación que les haga morir de éxito (Vera y Baños, 2010). Las principales técnicas utilizadas se basan en ampliar la oferta de actividades, y en la elaboración de planes de renovación, reorientación y redefinición del modelo turístico empleado (Vera y Baños, 2016; Simancas y Ledesma, 2016). Pero, esto puede cambiar en un futuro inmediato debido a la pandemia de la COVID-19. El turismo se ha visto afectado por otras crisis como la desatada tras el ataque terrorista en New York y Washington el 11 de septiembre de 2001 o tras la crisis económica de 2008. Esto sugiere que el sector ha sido resistente ante las crisis. Sin embargo, existen evidencias de que el impacto y la recuperación de la pandemia no tendrán precedentes (Gössling et al., 2020). La Organización Mundial del Turismo (UNWTO) considera que el sector turístico va a cambiar de forma sustancial durante los próximos años, siendo necesaria la reformulación y la innovación en los destinos con el fin de adaptarse a la nueva situación (UNWTO, 2020). Es decir, la COVID-19 marcará un antes y un después.

La Región de Murcia no es ajena a esta tesitura, conformando, tal y como afirmaban Andrés (2004 y 2007) y Serrano (2007), uno de los modelos turísticos más arcaico, lastrado y con mayor dicotomía interna (contrastes y pujanzas entre sus diversas áreas turísticas) del levante español.

\section{Objetivos, metodología y fuentes}

El artículo tiene como objetivo realizar un análisis de la actividad turística en el litoral de la Región de Murcia. El punto de partida se basa en indagar en la evolución y estado actual que presenta este sector en relación a otras provincias y regiones vecinas. Una vez contrastada la situación turística regional dentro de un contexto más amplio, se pretende examinar el peso que el turismo litoral posee sobre la totalidad del territorio murciano. Además, se investigan las diferencias existentes entre los distintos municipios costeros de la Región de Murcia. Para ello, se analiza una serie de indicadores relativos al volumen y reparto de la recepción y pernoctación turística, origen y residencia de los viajeros, 
evolución de establecimientos y plazas hoteleras, tipología, así como la categoría y la distribución de las infraestructuras turísticas.

La metodología seguida para abordar dichas cuestiones se inicia en la revisión en profundidad de literatura especializada publicada hasta la fecha. Seguidamente, se ha realizado una recopilación y contrastación de datos procedentes de diversas fuentes oficiales (Instituto Nacional de Estadística, Centro Regional de Estadística de la Región de Murcia, web oficial de turismo Murcia Turística, etc.). Estos datos se han tratado mediante el uso de hojas de cálculo (Excel) y software de diseño gráfico y cartográfico (Sistemas de Información Geográfica) de cara a la elaboración de resultados y conclusiones que indiquen el proceso, situación, fortalezas y debilidades que presenta el sector turístico de la Región de Murcia.

\section{Resultados}

\subsection{Contrastes interregionales}

El impacto que el sector turístico posee en las diferentes delimitaciones administrativas que estructuran el agregado español es dispar, manifestando acusadas discordancias interregionales (Domínguez, 2002). Entre las diferentes áreas de referencia turística nacional, el litoral mediterráneo se ha consolidado como el espacio de mayor relevancia (Figura 1). Se trata de un ámbito en el que, desde hace décadas, la actividad turística viene caracterizada por el marcado contraste estacional propio del turismo de masas (Coll y Seguí, 2014).

Figura 1: Mapa de localización CCAA y provincias del ámbito de estudio

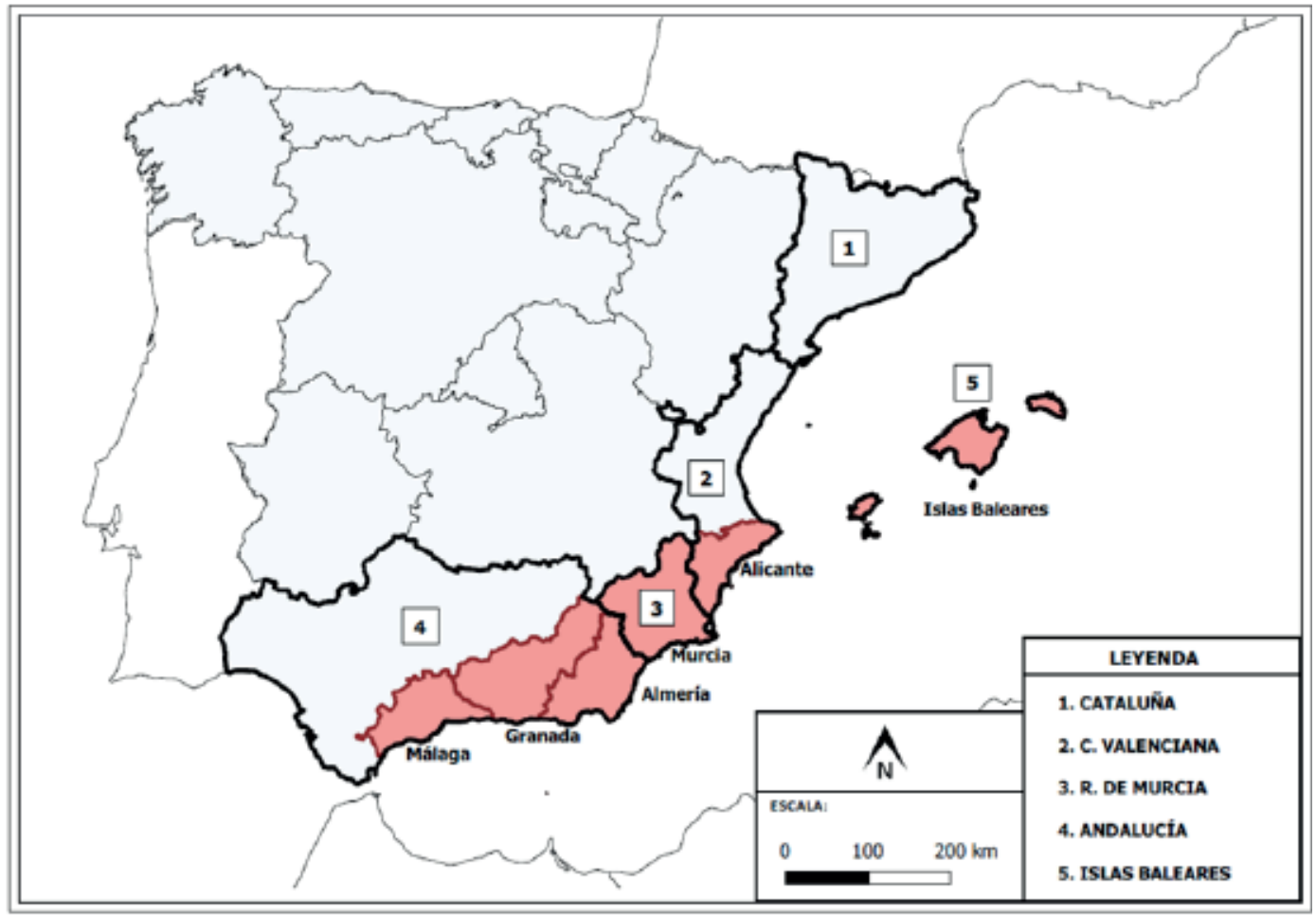

Fuente: Elaboración propia.

Es preciso resaltar que debido a su condición de Comunidad Autónoma uniprovicial, la Región de Murcia presenta menor importancia turística que las provincias y comunidades de su entorno (Serrano, 
2007). Para verificar tal observación, es necesario analizar diversos indicadores: registro de viajeros y pernoctaciones y la evolución de las plazas hoteleras ocupadas durante los últimos años, intentando contrastar con la totalidad de comunidades y provincias litorales mediterráneas (Tabla 1).

Tabla 1: Evolución de la recepción de turistas por CCAA y provincias

\begin{tabular}{|l|r|r|r|r|r|r|}
\hline & \multicolumn{1}{|c|}{$\mathbf{2 0 0 0}$} & \multicolumn{1}{c|}{$\mathbf{2 0 0 4}$} & \multicolumn{1}{c|}{$\mathbf{2 0 0 8}$} & \multicolumn{1}{c|}{$\mathbf{2 0 1 2}$} & \multicolumn{1}{c|}{$\mathbf{2 0 1 7}$} & \multicolumn{1}{c|}{2019} \\
\hline $\begin{array}{l}\text { Total } \\
\text { Nacional }\end{array}$ & $\mathbf{5 9 . 2 8 2 . 5 2 2}$ & $\mathbf{6 6 . 8 3 1 . 2 6 8}$ & $\mathbf{8 2 . 9 9 8 . 8 7 7}$ & $\mathbf{8 2 . 9 6 2 . 4 8 1}$ & $\mathbf{1 0 3 . 8 0 4 . 0 6 7}$ & $\mathbf{1 0 8 . 6 1 7 . 5 8 3}$ \\
\hline Andalucía & $\mathbf{1 1 . 1 6 8 . 1 1 8}$ & $\mathbf{1 2 . 5 3 4 . 7 7 9}$ & $\mathbf{1 5 . 7 6 9 . 3 3 9}$ & $\mathbf{1 4 . 4 5 1 . 5 8 7}$ & $\mathbf{1 8 . 4 2 9 . 6 9 2}$ & $\mathbf{1 9 . 8 4 5 . 3 6 1}$ \\
\hline Almería & 803.629 & 1.134 .094 & 1.296 .727 & 1.015 .062 & 1.407 .222 & 1.494 .201 \\
\hline Granada & 1.743 .485 & 1.921 .108 & 2.256 .909 & 2.221 .897 & 2.856 .323 & 3.263 .605 \\
\hline Málaga & 3.298 .647 & 3.575 .088 & 4.917 .794 & 4.323 .141 & 5.410 .226 & 5.826 .800 \\
\hline Cataluña & $\mathbf{1 0 . 1 6 3 . 3 1 8}$ & $\mathbf{1 1 . 5 5 8 . 7 1 8}$ & $\mathbf{1 4 . 4 3 7 . 7 2 8}$ & $\mathbf{1 6 . 2 3 6 . 9 4 1}$ & $\mathbf{1 9 . 7 7 1 . 9 6 7}$ & $\mathbf{2 0 . 7 4 2 . 7 2 1}$ \\
\hline $\begin{array}{l}\text { Comunidad } \\
\text { Valenciana }\end{array}$ & $\mathbf{4 . 4 9 8 . 6 2 3}$ & $\mathbf{5 . 8 6 5 . 6 9 7}$ & $\mathbf{7 . 2 8 1 . 5 9 7}$ & $\mathbf{6 . 9 3 3 . 7 5 3}$ & $\mathbf{8 . 7 0 7 . 1 7 7}$ & $\mathbf{9 . 3 3 7 . 6 5 7}$ \\
\hline $\begin{array}{l}\text { Alicante/ } \\
\text { Alacant }\end{array}$ & 2.553 .520 & 3.124 .636 & 3.485 .496 & 3.426 .910 & 4.385 .308 & 4.583 .700 \\
\hline $\begin{array}{l}\text { Islas } \\
\text { Baleares }\end{array}$ & $\mathbf{6 . 6 8 7 . 5 6 9}$ & $\mathbf{6 . 8 6 8 . 7 3 7}$ & $\mathbf{7 . 9 6 3 . 0 7 4}$ & $\mathbf{8 . 4 6 1 . 8 5 5}$ & $\mathbf{1 0 . 1 6 5 . 0 5 8}$ & $\mathbf{1 0 . 6 0 6 . 1 8 4}$ \\
\hline $\begin{array}{l}\text { Región de } \\
\text { Murcia }\end{array}$ & $\mathbf{7 6 7 . 3 9 4}$ & $\mathbf{1 . 0 0 0 . 1 3 6}$ & $\mathbf{1 . 1 7 1 . 4 2 5}$ & $\mathbf{1 . 0 1 0 . 5 3 8}$ & $\mathbf{1 . 2 9 3 . 0 3 8}$ & $\mathbf{1 . 3 6 5 . 8 7 5}$ \\
\hline
\end{tabular}

Fuente: Instituto Nacional de Estadística (INE).

A pesar de contar con una superficie superior al del resto de provincias y más de $200 \mathrm{~km}$ de costa, la Región de Murcia ostenta el valor de recepción turística más bajo de los analizados. La notoriedad de los datos de viajeros que eligen como destino turístico esta delimitación administrativa es tan escasa a escala autonómica que apenas se hace incomparable con las más punteras (Figura 2), representando en torno al 1,3\% del total de personas que visitan el país, lejos de Cataluña $(19,1 \%)$, Baleares $(9,8 \%)$, o la Comunidad Valenciana (8,6\%).

Figura 2: Porcentaje de turistas que llegan anualmente a las CCAA del litoral mediterráneo.

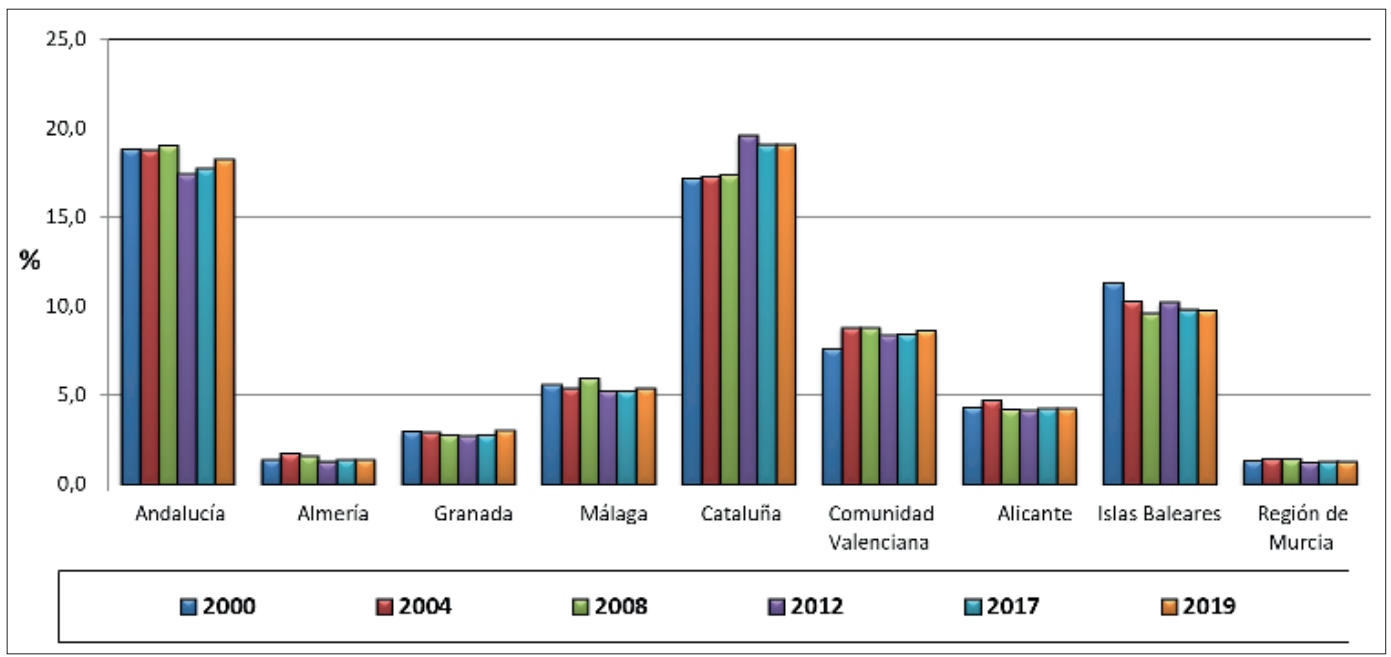

Fuente: Elaboración propia a través de los datos del INE. 
A nivel provincial los datos siguen siendo elocuentes, obteniendo los registros más bajos de las delimitaciones indagadas. A pesar de ello, los valores anuales se mantienen muy cerca de los obtenidos por Almería, siendo netamente inferiores a los que presentan el resto de provincias.

El reparto porcentual de individuos que llegan a la costa mediterránea muestra los efectos de la recesión económica, inestabilidad que propicia el retroceso de la recepción turística (Torres et al., 2014). El acusado descenso de turistas se puede achacar, previsiblemente, a la potencialización del turismo interior, con destinos más económicos que el litoral (Cànoves et al., 2012).

$\mathrm{Al}$ igual que sucede con el destino turístico, el origen de los viajeros es relativamente equitativo a nivel nacional y eminentemente disímil a escala autonómica y provincial (Tabla 2).

Tabla 2: Evolución del reparto porcentual (\%) de los turistas en función de residencia (R: Residente - NR: No Residente)

\begin{tabular}{|l|c|c|c|c|c|c|c|c|c|c|c|c|}
\hline & \multicolumn{2}{|c|}{$\mathbf{2 0 0 0}$} & \multicolumn{2}{|c|}{$\mathbf{2 0 0 4}$} & \multicolumn{2}{c|}{$\mathbf{2 0 0 8}$} & \multicolumn{2}{c|}{$\mathbf{2 0 1 2}$} & \multicolumn{2}{|c|}{$\mathbf{2 0 1 7}$} & \multicolumn{2}{|c|}{$\mathbf{2 0 1 9}$} \\
\hline & $\mathbf{R}$ & $\mathbf{N R}$ & $\mathbf{R}$ & $\mathbf{N R}$ & $\mathbf{R}$ & $\mathbf{N R}$ & $\mathbf{R}$ & $\mathbf{N R}$ & $\mathbf{R}$ & $\mathbf{N R}$ & $\mathbf{R}$ & $\mathbf{N}$ \\
\hline $\begin{array}{l}\text { Total } \\
\text { Nacional }\end{array}$ & $\mathbf{5 4 , 2}$ & $\mathbf{4 5 , 8}$ & $\mathbf{5 8 , 7}$ & $\mathbf{4 1 , 3}$ & $\mathbf{5 6 , 9}$ & $\mathbf{4 3 , 1}$ & $\mathbf{5 1 , 9}$ & $\mathbf{4 8 , 1}$ & $\mathbf{4 8 , 6}$ & $\mathbf{5 1 , 4}$ & 48,5 & 51,5 \\
\hline Andalucía & $\mathbf{5 3 , 2}$ & $\mathbf{4 6 , 8}$ & $\mathbf{6 1 , 1}$ & $\mathbf{3 8 , 9}$ & $\mathbf{6 2 , 4}$ & $\mathbf{3 7 , 6}$ & $\mathbf{5 7 , 8}$ & $\mathbf{4 2 , 2}$ & $\mathbf{5 1 , 8}$ & $\mathbf{4 8 , 2}$ & 52,9 & 47,1 \\
\hline Almería & 66,3 & 33,7 & 78,2 & 21,8 & 83,1 & 16,9 & 83,9 & 16,1 & 74,7 & 25,3 & 77,0 & 23,0 \\
\hline Granada & 51,2 & 48,8 & 58,8 & 41,2 & 61,4 & 38,6 & 57,5 & 42,5 & 52,5 & 47,5 & 52,3 & 47,7 \\
\hline Málaga & 39,3 & 60,7 & 46,7 & 53,3 & 49,0 & 51,0 & 44,4 & 55,6 & 35,9 & 64,1 & 37,9 & 62,1 \\
\hline Cataluña & $\mathbf{6 6 , 0}$ & $\mathbf{3 4 , 0}$ & $\mathbf{7 0 , 3}$ & $\mathbf{2 9 , 7}$ & $\mathbf{6 6 , 3}$ & $\mathbf{3 3 , 7}$ & $\mathbf{6 4 , 7}$ & $\mathbf{3 5 , 3}$ & $\mathbf{5 9 , 4}$ & $\mathbf{4 0 , 6}$ & 35,3 & 64,7 \\
\hline $\begin{array}{l}\text { Comunidad } \\
\text { Valenciana }\end{array}$ & $\mathbf{6 0 , 8}$ & $\mathbf{3 9 , 2}$ & $\mathbf{6 3 , 8}$ & $\mathbf{3 6 , 2}$ & $\mathbf{6 2 , 0}$ & $\mathbf{3 8 , 0}$ & $\mathbf{6 1 , 7}$ & $\mathbf{3 8 , 4}$ & $\mathbf{5 3 , 5}$ & $\mathbf{4 6 , 5}$ & 59,2 & 40,8 \\
\hline Alicante & 44,6 & 55,4 & 45,3 & 54,7 & 42,2 & 57,8 & 38,8 & 61,2 & 37,7 & 62,3 & 55,8 & 44,2 \\
\hline $\begin{array}{l}\text { Islas } \\
\text { Baleares }\end{array}$ & $\mathbf{1 6 , 9}$ & $\mathbf{8 4 , 0}$ & $\mathbf{1 8 , 0}$ & $\mathbf{8 3 , 2}$ & $\mathbf{1 9 , 9}$ & $\mathbf{8 0 , 6}$ & $\mathbf{1 3 , 7}$ & $\mathbf{8 6 , 3}$ & $\mathbf{1 3 , 2}$ & $\mathbf{8 6 , 8}$ & 13,0 & 87,0 \\
\hline $\begin{array}{l}\text { Región de } \\
\text { Murcia }\end{array}$ & $\mathbf{8 4 , 4}$ & $\mathbf{1 5 , 6}$ & $\mathbf{8 2 , 0}$ & $\mathbf{1 8 , 0}$ & $\mathbf{8 2 , 1}$ & $\mathbf{1 7 , 9}$ & $\mathbf{8 2 , 9}$ & $\mathbf{1 7 , 1}$ & $\mathbf{7 8 , 0}$ & $\mathbf{2 2 , 0}$ & 77,9 & 22,1 \\
\hline
\end{tabular}

Fuente: Elaboración propia a través de los datos del INE.

El reparto de viajeros en función de procedencia ha sido variado desde el inicio del nuevo milenio. El cómputo global de los mismos muestra que España ha pasado de ser un destino turístico donde predominaba la población residente en el propio territorio nacional, a constituir un espacio de turistas residentes en el exterior de los límites administrativos del mismo. La presencia de turistas residentes fuera de España se ha ido agudizando conforme la serie se aproxima a la actualidad, manifestando su punto de inflexión durante los últimos años de la primera década del siglo XXI. Casualmente, dicha fecha coincide con el estallido de la burbuja inmobiliaria y el inicio de la crisis económica y financiera generada por la misma (Daher, 2013). A pesar de que la desaceleración económica afectó a escala global, la inestabilidad política experimentada por España durante estos años ha provocado que la recuperación financiera sea más costosa y tardía que en otros países, lo que ha llevado consigo que la renta per cápita de sus ciudadanos disminuya y cuenten con mayor dificultad para realizar desplazamientos con fines de ocio y recreación (Giménez et al., 2018a). La mencionada hipótesis muestra diversas contradicciones que se hacen palpables especialmente en Murcia y Almería. En ambos espacios, el reparto de los turistas en función de su origen muestra un comportamiento heterogéneo, con un claro predominio de individuos de residencia nacional. Este balance contrasta con el observado en áreas de tradición turística internacional (Baleares y Málaga), espacios donde las prácticas de ocio nocturno y la adaptación a la cultura anglosajona han provocado que cerca del $90 \%$ de los turistas que reciben procedan de fuera del país.

Como es lógico, los datos de pernoctación siguen una tendencia paralela a los de recepción viajera. De tal forma, la totalidad de la superficie nacional ha hospedado en 2019 a más de 343 millones de personas. Gran parte de estos viajeros se alojan a orillas del mediterráneo (59,6\%), principalmente en Baleares (16,98\%), Cataluña (16,97\%) y Andalucía (16\%) (Tabla 3). 
Tabla 3: Evolución de las pernoctaciones.

\begin{tabular}{|l|r|r|r|r|r|r|}
\hline & \multicolumn{1}{|c|}{$\mathbf{2 0 0 0}$} & \multicolumn{1}{c|}{$\mathbf{2 0 0 4}$} & \multicolumn{1}{c|}{$\mathbf{2 0 0 8}$} & \multicolumn{1}{c|}{$\mathbf{2 0 1 2}$} & \multicolumn{1}{c|}{$\mathbf{2 0 1 7}$} & \multicolumn{1}{c|}{$\mathbf{2 0 1 9}$} \\
\hline Total Nacional & $\mathbf{2 2 7 . 1 4 3 . 5 7 2}$ & $\mathbf{2 3 4 . 6 9 7 . 1 6 4}$ & $\mathbf{2 6 8 . 5 5 1 . 8 4 0}$ & $\mathbf{2 8 0 . 6 5 9 . 5 4 8}$ & $\mathbf{3 4 0 . 5 8 2 . 7 1 2}$ & $\mathbf{3 4 3 . 1 6 3 . 7 9 6}$ \\
\hline Andalucía & $\mathbf{3 4 . 5 2 9 . 9 5 4}$ & $\mathbf{3 8 . 8 4 6 . 2 2 7}$ & $\mathbf{4 4 . 1 7 1 . 5 4 9}$ & $\mathbf{4 1 . 1 8 1 . 7 6 4}$ & $\mathbf{5 2 . 5 6 1 . 1 8 8}$ & $\mathbf{5 4 . 9 2 2 . 4 4 2}$ \\
\hline Almería & 4.113 .850 & 5.038 .017 & 4.915 .760 & 4.105 .705 & 5.552 .819 & 5.389 .698 \\
\hline Granada & 3.471 .945 & 4.094 .539 & 4.762 .288 & 4.639 .705 & 5.919 .493 & 6.586 .197 \\
\hline Málaga & 15.074 .225 & 15.048 .178 & 17.430 .627 & 16.062 .932 & 19.942 .144 & 20.374 .862 \\
\hline $\begin{array}{l}\text { Comunidad } \\
\text { Valenciana }\end{array}$ & $\mathbf{2 0 . 0 8 2 . 2 5 1}$ & $\mathbf{2 1 . 6 5 9 . 8 5 3}$ & $\mathbf{2 4 . 5 3 1 . 9 8 2}$ & $\mathbf{2 3 . 9 8 1 . 6 7 0}$ & $\mathbf{2 9 . 1 8 6 . 3 2 5}$ & $\mathbf{2 9 . 8 6 6 . 0 6 3}$ \\
\hline Alicante & 14.500 .661 & 14.037 .830 & 14.973 .769 & 14.930 .472 & 18.049 .863 & 17.881 .245 \\
\hline Cataluña & $\mathbf{3 6 . 8 0 2 . 6 7 1}$ & $\mathbf{3 8 . 1 1 5 . 8 5 9}$ & $\mathbf{4 2 . 1 5 0 . 2 4 2}$ & $\mathbf{4 8 . 3 7 6 . 5 3 5}$ & $\mathbf{5 7 . 2 2 0 . 4 5 3}$ & $\mathbf{5 8 . 2 5 8 . 4 3 7}$ \\
\hline Islas Baleares & $\mathbf{5 2 . 4 4 9 . 1 8 5}$ & $\mathbf{4 7 . 3 0 6 . 7 0 0}$ & $\mathbf{4 9 . 0 5 8 . 3 8 4}$ & $\mathbf{5 4 . 2 4 2 . 0 9 8}$ & $\mathbf{5 9 . 3 7 5 . 9 3 9}$ & $\mathbf{5 8 . 2 9 7 . 3 2 9}$ \\
\hline $\begin{array}{l}\text { Región de } \\
\text { Murcia }\end{array}$ & $\mathbf{2 . 4 1 5 . 0 3 0}$ & $\mathbf{2 . 6 0 4 . 6 5 2}$ & $\mathbf{2 . 9 5 4 . 0 5 5}$ & $\mathbf{2 . 5 3 7 . 4 2 7}$ & $\mathbf{3 . 1 4 3 . 2 5 5}$ & $\mathbf{3 . 2 8 5 . 1 5 8}$ \\
\hline
\end{tabular}

Fuente: Elaboración propia a través de los datos del INE.

De toda la franja litoral mediterránea analizada, las comunidades levantinas son las que menor peso pernoctacional poseen, constituyendo el caso de la Región de Murcia el valor de menor significación (1,06\% de los hospedajes nacionales). La cifra de huéspedes que hacen noche en instalaciones hoteleras y alojamientos turísticos murcianos apenas se ha incrementado en un millón de individuos durante dos últimas décadas.

Para conocer las razones que han llevado a tal precariedad pernoctacional, se debe analizar el equipamiento hotelero ofrecido por esta región y la renovación del mismo (Tabla 4).

Tabla 4: Evolución plazas hoteleras (hoteles y pensiones)

\begin{tabular}{|l|r|r|r|r|r|r|r|r|}
\hline & \multicolumn{1}{|c|}{$\mathbf{1 9 6 2}$} & \multicolumn{1}{|c|}{$\mathbf{1 9 7 7}$} & $\mathbf{1 9 8 4}$ & \multicolumn{1}{l|}{$\mathbf{1 9 9 6}$} & \multicolumn{1}{l}{$\mathbf{2 0 0 0}$} & \multicolumn{1}{l|}{$\mathbf{2 0 0 8}$} & \multicolumn{1}{l|}{$\mathbf{2 0 1 2}$} & \multicolumn{1}{l}{$\mathbf{2 0 1 9}$} \\
\hline $\begin{array}{l}\text { Total } \\
\text { Nacional }\end{array}$ & 162.105 & 798.985 & 835.200 & 1.025 .208 & 1.315 .697 & 1.615 .249 & 1.746 .785 & 1.855 .939 \\
\hline Baleares & 19.766 & 226.754 & 227.245 & 258.513 & 314.666 & 320.673 & 339.453 & 362.786 \\
\hline Málaga & 5.856 & 47.155 & 47.684 & 50.394 & 67.865 & 91.988 & 92.364 & 101.950 \\
\hline Alicante & 4.962 & 49.091 & 49.091 & 50.093 & 56.783 & 69.046 & 73.291 & 78.520 \\
\hline Almería & 284 & 8.646 & 9.278 & 16.546 & 22.425 & 34.209 & 37.987 & 43.591 \\
\hline Granada & 4.386 & 10.481 & 12.652 & 18.184 & 23.003 & 27.121 & 30.106 & 33.752 \\
\hline Murcia & 1.973 & 8.100 & 10.299 & 13.218 & 15.560 & 19.490 & 19.845 & 19.802 \\
\hline
\end{tabular}

Fuente: Elaboración propia a través de los datos del INE.

Los datos evidencian que Murcia se ha descolgado paulatinamente del desarrollo lógico llevado a cabo por el resto de provincias inmediatas, en cuanto a equipamiento hotelero se refiere. Es de reseñar que durante los 57 años transcurridos, el equipamiento hotelero nacional se ha multiplicado por 12 (aprox.), registrando el mayor incremento durante los primeros tres lustros de la serie. El periodo 1962-1977 constituye el momento de eclosión turística del país, con un incremento desmesurado de camas de hotel. Dicho proceso afectó notablemente a las provincias estudiadas, áreas que en 1977 acogían prácticamente la mitad de las plazas hoteleras del país (43,8\%). Entre las diferentes entidades observadas en la citada anualidad, cobraba gran relevancia el archipiélago balear, ya que suponía el 28,4\% de las mismas. 
De forma general, salvo Murcia y Granada, el conjunto de provincias examinadas han aumentado su cuota de participación durante el más de medio siglo analizado, lo que supone un incremento desmesurado. Si se tienen en cuenta que en 1962 tan solo se contemplaban 284 plazas, Almería es la provincia con el crecimiento exponencial más relevante (15.348,94\%). El incremento de equipamientos en esta provincia andaluza ha sido tan vertiginoso que a día de hoy acoge más del doble de camas de hotel que la Región de Murcia, aspecto a tener en cuenta debido a que la dotación existente en ésta durante el primer año de la serie era seis veces superior a la almeriense. El estancamiento experimentado durante la última década por la Región de Murcia es notable; se trata de la única provincia de las estudiadas que ha reducido el número de plazas durante el último lustro. Este territorio apenas ha participado en el proceso de desarrollo turístico experimentado a nivel nacional, aspecto que incita a recapacitar sobre las causas que la han llevado a tal estancamiento. Para ello, es necesario realizar una reflexión concisa que muestre los hechos que lastran el devenir de esta región y han provocado que haya quedado al margen del "exitoso" modelo turístico mediterráneo.

Entre los hechos de mayor significación cabe recordar y reforzar, de forma breve, los propuestos por Serrano (2007):

- Accesibilidad: posiblemente, los problemas de comunicación terrestre y aérea han sido el mayor escollo que ha tenido que driblar esta región. La Autopista del Mediterráneo (AP-7) no llegó a suelo murciano hasta bien avanzados los años 90 del pasado siglo, prácticamente una década más tarde que a Alicante. Una vez construida dicha vía, cabe señalar que el enlace con Almería discurre un tanto retirado del litoral, hecho que, a diferencia de los lugares por donde traza su recorrido el resto del eje de comunicación, obstaculiza el aprovechamiento turístico del mismo. La situación ferroviaria es similar, ya que a diferencia de otras provincias observadas la llegada de la alta velocidad (AVE) se sigue retrasando (Serrano, 2016). El conflicto sobre el soterramiento de las vías no ha provocado más que demoras en la construcción, y a día de hoy no conoce una fecha exacta para su inauguración. Por su parte, mientras que Alicante y Málaga cuentan con aeropuertos de referencia nacional, y tanto Almería como Granada con instalaciones aéreas desde hace más de cuatro décadas, el transporte aéreo murciano ha dependido históricamente de la combinación entre las infraestructuras de provincias vecinas y un de un aeropuerto militar-civil propio (San Javier) (Serrano, 2001, Serrano et al., 2016). Cabe mencionar, que la región cuenta con un aeropuerto internacional (Corvera) que acaba de comenzar su actividad en enero de 2019.

- Escasa inversión de capital: tradicionalmente, el sector turístico murciano ha carecido de cualquier tipo de inversión que impulse la renovación y desarrollo del equipamiento hotelero. Los grupos de inversión extranjeros son escasos, y la apuesta del gobierno central y regional por la actividad turística murciana, hasta el momento, no ha sido suficiente para hacer frente a la oferta de las áreas vecinas.

- Recesión económica: durante la última década del pasado siglo, comienza a brotar en las áreas litorales y prelitorales regionales una cierta tendencia turística basada en la construcción de complejos residenciales (tipo resort) que pretendían cubrir la amplia demanda de segunda residencia presente en aquellos años (Serrano, 1993; Pontes et al., 2018). La guerra por la escasez del agua, unido a la llegada de la crisis económica, zanjó el desarrollo de estos proyectos, creando inmensas ciudades fantasma y dejando un descomunal stock de viviendas (tanto construidas como a medio construir). Muchas de estas urbanizaciones orientadas en un principio a la recepción de turismo foráneo y segunda residencia pudieron salir adelante al ser aprovechadas como vivienda primaria de la población que reside y trabaja en las proximidades. Se trata, fundamentalmente, de urbanizaciones proyectadas al amparo de grandes centros urbanos y que en la actualidad ejercen la función de ciudades satélite o dormitorio (Giménez et al., 2018b).

- Esfuerzo político: a pesar de las diversas campañas publicitarias (Murcia Turística o Murcia No-Typical) que pretendían resaltar las bondades turísticas de esta región, no se manifestó una clara voluntad política (ni estatal ni regional) que alzase el sector como una verdadera prioridad en este territorio.

\subsection{Caso de estudio: la Región de Murcia}

Para profundizar en los aspectos e indicadores más relevantes de esta región es necesario contrastar el peso que el turismo costero posee sobre la totalidad territorial, investigando los aspectos más representativos de las principales áreas turísticas litorales murcianas (Figura 3). 
Figura 3: Mapa de localización de las principales áreas turísticas de la Región de Murcia.

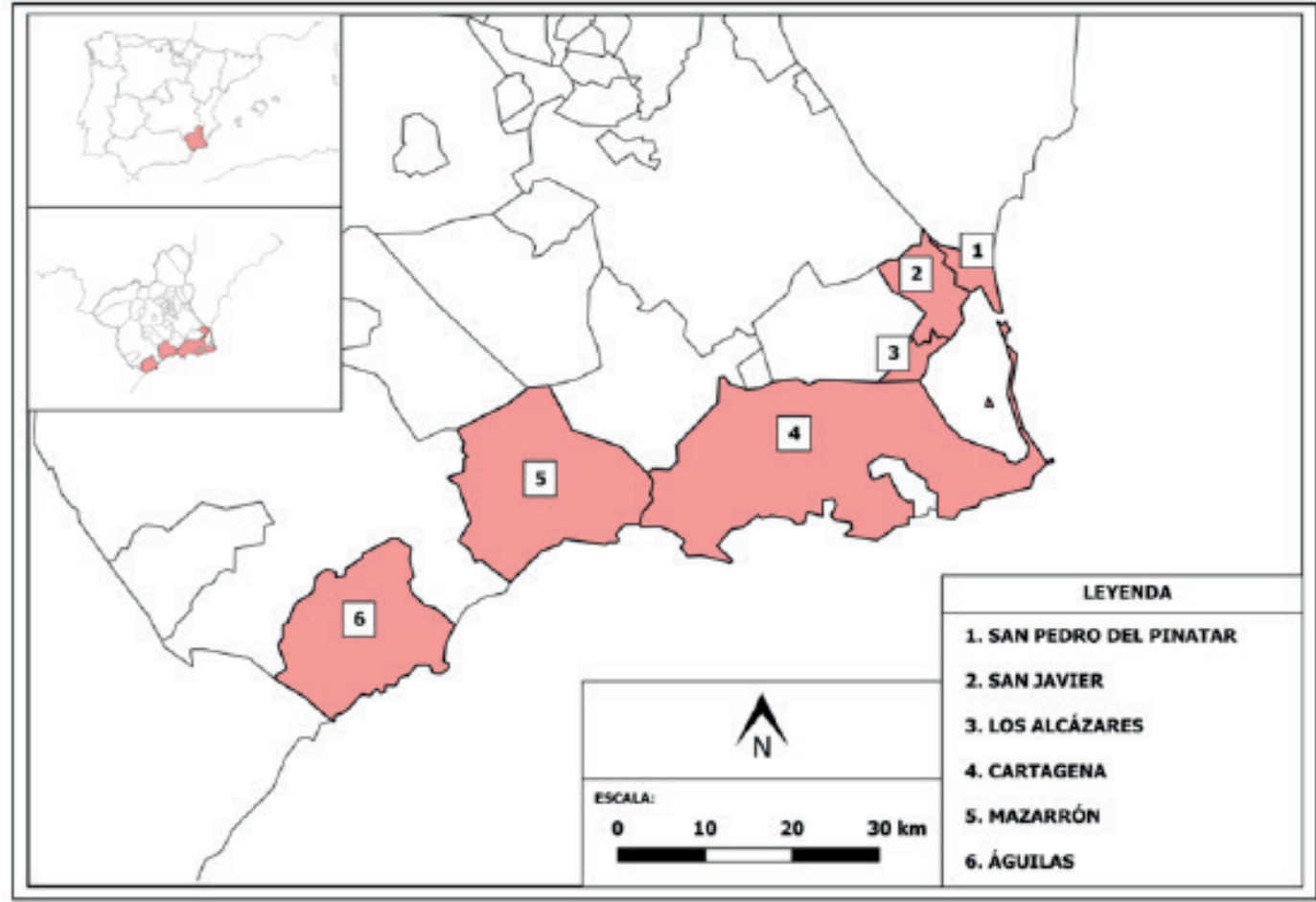

Fuente: Elaboración propia.

Se han delimitado cuatro áreas turística de referencia, obviando los municipios de Lorca y La Unión, localidades en las que el desarrollo turístico se ha visto lastrado por la escasez de kilómetros de costa, cantidad y calidad de los equipamientos cerca de la misma, la pésima accesibilidad de sus playas y su orientación hacia otro tipo de actividades económicas. Por tanto, los espacios a analizar se corresponden con La Manga (restinga marina que pertenece a los municipios de Cartagena y San Javier), resto del Mar Menor (demarcación correspondiente a los municipios de San Pedro del Pinatar, San Javier, Los Alcázares y la vertiente cartagenera que delimita la laguna salobre), Mazarrón y Águilas.

\subsubsection{Análisis de la recepción de turistas}

Como ya se mencionó anteriormente, el desarrollo turístico de la Región de Murcia no ha sido tan acusado como en el resto de provincias de su entorno mediterráneo. A pesar de ello, el volumen de recepción turística de este territorio muestra una tendencia positiva hasta 2007, año en el que supera el millón doscientos cincuenta mil turistas acogidos. Posteriormente, la crisis económica comenzó a afectar a la mayor parte de países desarrollados del planeta, lo que supuso que la renta de un gran segmento de la sociedad se viera mermada y los ciudadanos redujeran los desplazamientos por motivos de ocio y recreación (Figura 4).

El descenso del valor total de turistas también tuvo repercusión en el litoral murciano, con la pérdida de casi 15 mil viajeros anuales entre 2008 y 2011. Con el inicio de la segunda década del siglo XXI esta tendencia comenzó a estabilizarse, observando una paulatina recuperación que, a día de hoy, ha logrado sobreponerse y superar la cifra de viajeros registrada en 2007.

Conviene advertir que a pesar de que los efectos del ciclo económico repercutieron sobre el litoral, la cantidad de desplazamientos realizados hacia los municipios costeros por los ciudadanos de la propia Región de Murcia no ha sufrido variaciones tan contrastadas, manteniendo una cifra relativamente estable (cercana a 1/3 del total regional) hasta el año 2017. Sin embargo, la significación bajó hasta el $20,5 \%$ en 2018 y al $25,4 \%$ en 2019 . 
Figura 4: Evolución del turismo regional que llega a la costa de la R. de Murcia

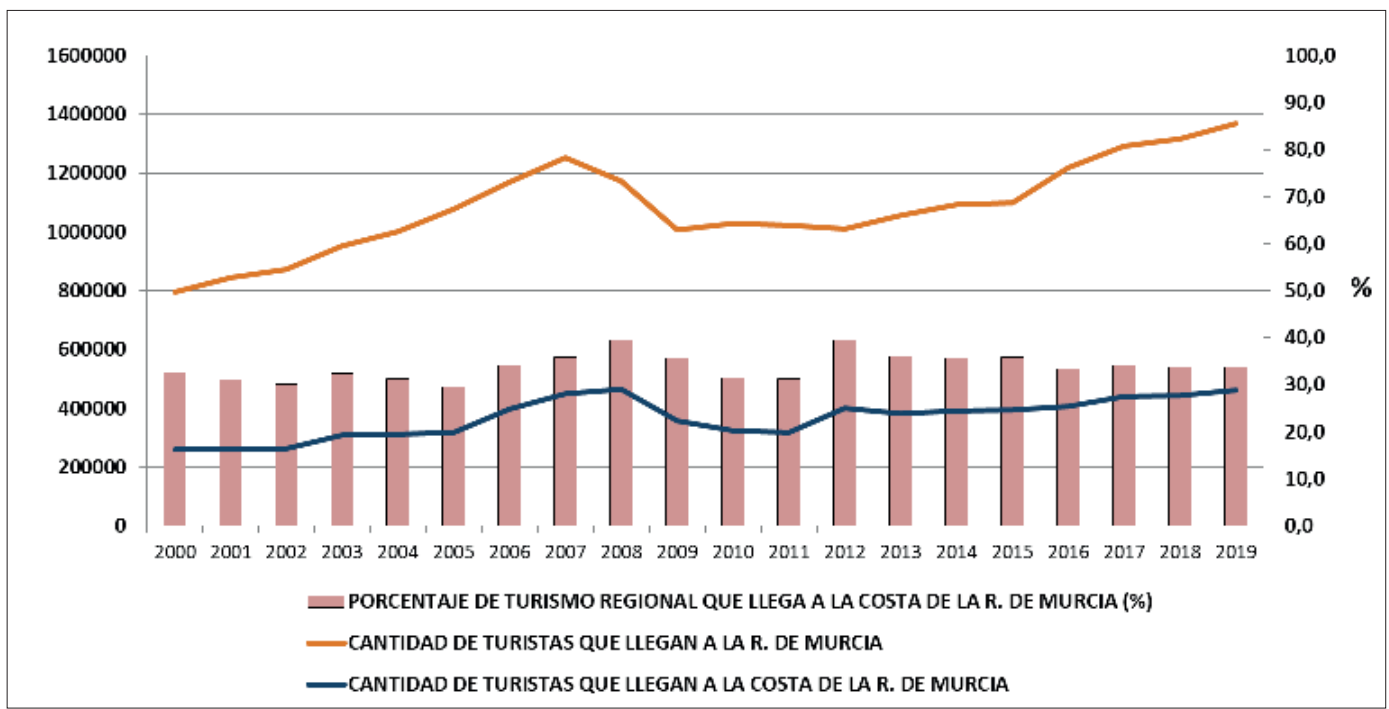

Fuente: Elaboración propia a través de los datos de Murcia Turística.

Los individuos llegados a este litoral no se repartieron de forma uniforme entre las diferentes área turísticas analizadas, mostrando un abrumador contraste entre los espacios costeros ubicados en la vertiente SE (La Manga y resto de Mar Menor) y los emplazados al SW (Mazarrón y Águilas) (Figura 5).

Figura 5: Evolución porcentual del reparto de turistas llegados a las principales áreas de la costa murciana

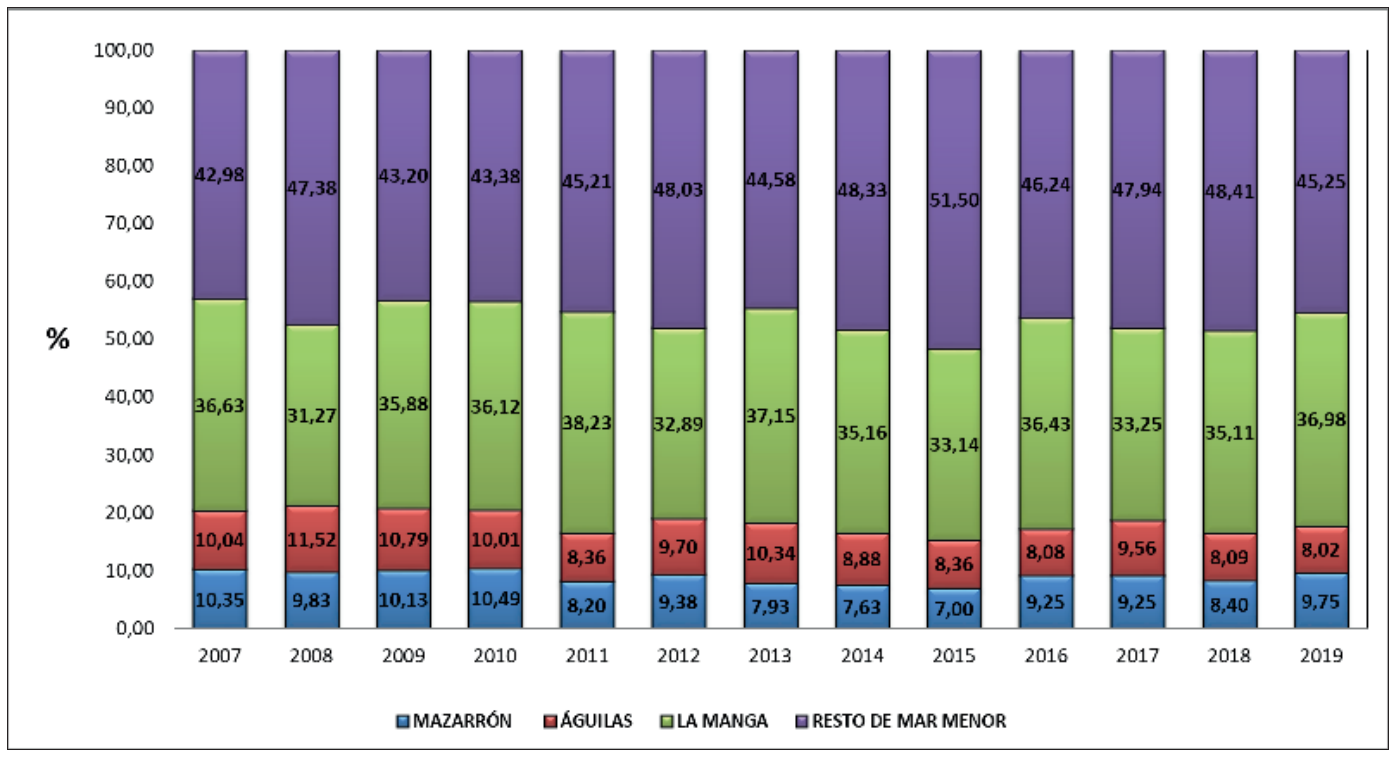

Fuente: Elaboración propia a través de los datos de Murcia Turística. 
La Manga y los municipios ubicados en torno al Mar Menor son los espacios de mayor tradición veraniega regional, acogiendo más del 80\% del turismo que llega al litoral. Entre ambas demarcaciones, el resto del Mar Menor constituye el territorio más frecuentado, llegando a atender a más de 200 mil turistas en 2015 (51,5\% del que llega al litoral regional). No obstante, en los últimos años la cifra se han reducido (45,25\% en 2019). Por su parte, La Manga constituye el espacio de mayor presión, superando los 44 mil turistas por $\mathrm{km}^{2}$ en el año 2007.

La aportación de Águilas y Mazarrón es en cierto modo escasa, representando cada municipio en torno al $10 \%$ del total.

\subsubsection{Evolución del origen de los turistas}

El origen de los viajeros que pernoctan en la Región de Murcia presenta un carácter dispar. Así, 8 de cada 10 turistas que llegan a la región residen en el mismo país de origen (Figura 6).

\section{Figura 6: Evolución de los turistas que llegan a la R. de Murcia en función de si residen o no en España}

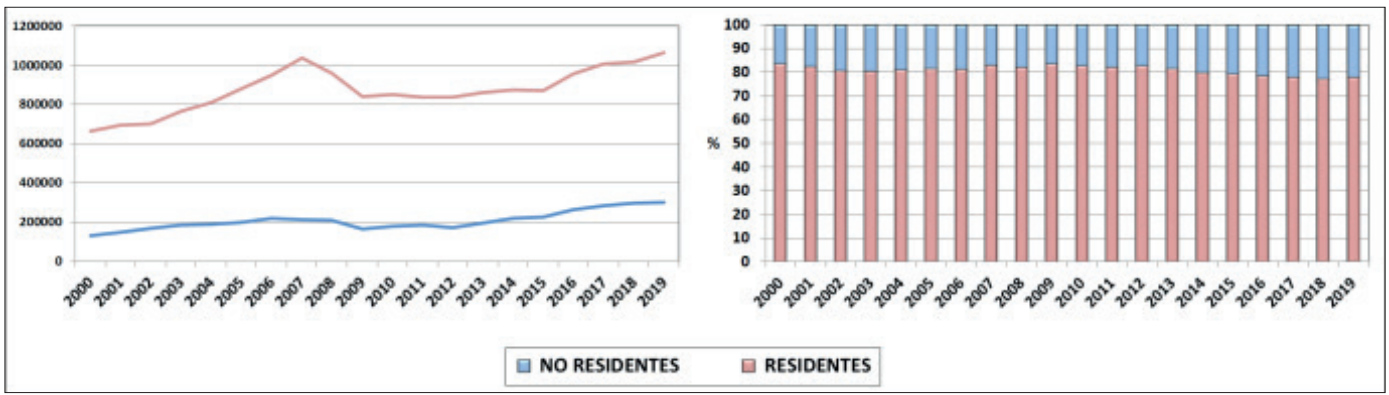

Fuente: Elaboración propia a través de los datos de Murcia Turística.

La evolución experimentada por ambas variables en las últimas dos décadas refleja, entre otros aspectos, el efecto que la recesión económica tuvo sobre el sector. Se aprecia como durante los años de bonanza económica nacional la movilidad de personas residentes en dicho territorio fue exponencial, llegando a superar el millón de turistas en 2007. Durante las siguientes anualidades esta actividad se vio gravemente afectada por las dificultades económicas que atravesaba el país, con una fuerte caída de las recepciones, tendencia que ha vuelto a brotar en la actualidad, volviendo a situarse en valores próximos a los años anteriores a la crisis.

La procedencia de los viajeros nacionales que llegan a la Región de Murcia es variada. No obstante, la mayoría proviene desde las autonomías de Madrid, Andalucía, Comunidad Valenciana y la propia Región de Murcia (Figura 7). En este sentido, cabe resaltar que en 2019 aglutinaron el 75\% de los turistas nacionales llegados a la Región de Murcia, porcentaje que se ha mantenido más o menos constante desde el año 2000.

Por otro lado, los valores porcentuales han variado desde comienzos del siglo XXI (Figura 7). Por ejemplo, en los viajeros de la propia Región de Murcia se observa un importante crecimiento de su significación, ya que en el año 2000 suponían un 13\% del total, mientras que en 2019 aportó casi un cuarto (24\%). Este incremento puede justificarse en la mejora de la red de carreteras regionales que se ha producido en los últimos lustros que han supuesto una mayor conectividad interior, así como de las motivaciones de los murcianos en conocer su territorio. Por su parte, los turistas procedentes de la Comunidad de Madrid han visto disminuida su importancia, pasando de liderar la estadística en el año 2000 con el 23\% de los viajeros a ser la tercera Comunidad Autónoma en importancia en 2019 con el 17\%. Por último, Andalucía y la Comunidad Valenciana se han mantenido más o menos constantes, aunque esta última ha superado a Madrid y se ha colocado en segunda posición en 2019.

En cuanto al flujo de turistas que residen fuera de España, procede advertir que éstos han sufrido una evolución más estable, situándose en torno a las 200 mil llegadas anuales. La crisis económica en los países de origen de los turistas (fundamentalmente Europa) fue menos intensa y tuvo una recuperación más ágil que en España (Fernández, 2016), lo que supuso que la oleada de viajeros apenas se resintiera. 
Figura 7: Evolución porcentual de los turistas nacionales que llegan a la Región de Murcia en función de la Comunidad Autónoma de procedencia

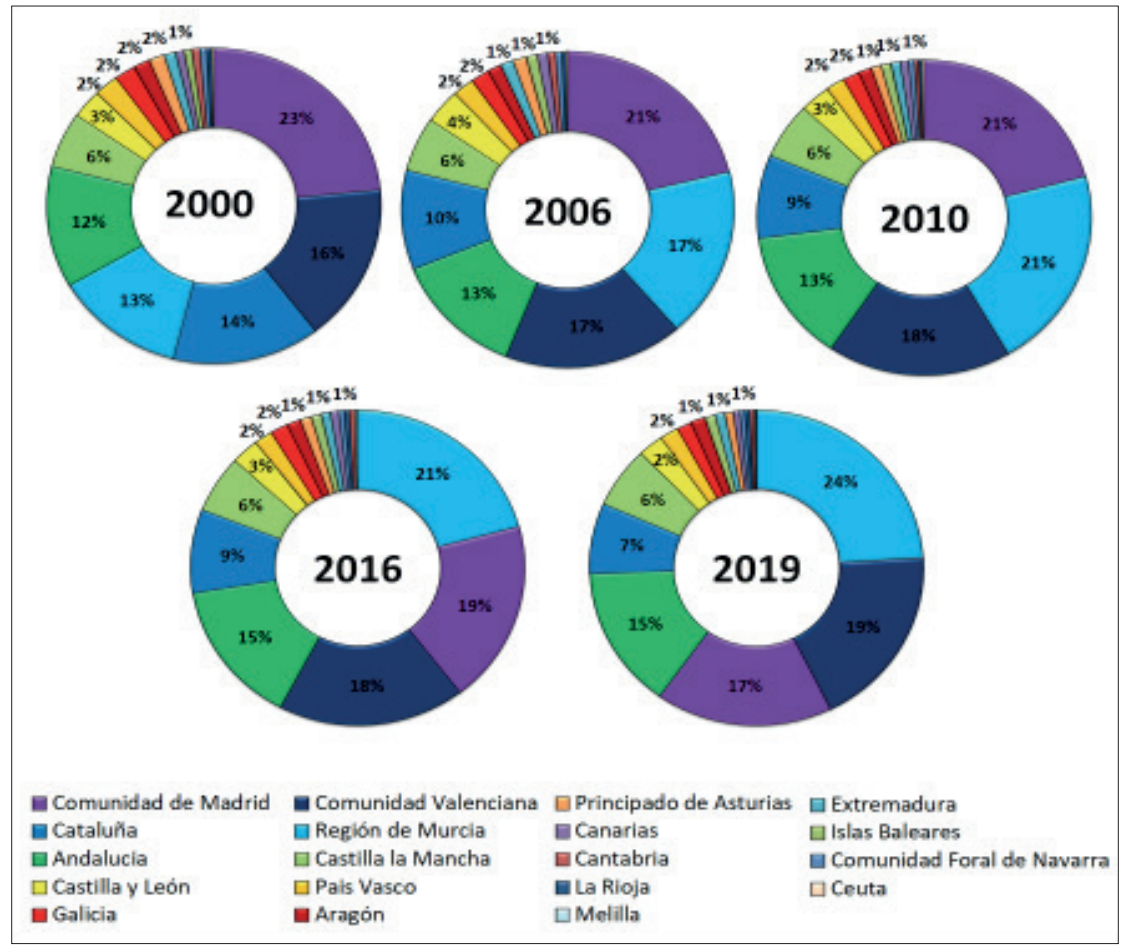

Fuente: Elaboración propia a través de los datos de Murcia Turística.

Europa es el continente de procedencia de prácticamente el 80\% de los turistas con residencia extranjera. Por otro lado, los viajeros procedentes de América se estiman en un 10\%, esto es debido a las visitas que realizan los familiares de los inmigrantes sudamericanos afincados en la Región de Murcia (Tabla 5).

Tabla 5: Reparto porcentual de los turistas que llegan a la R. de Murcia en función del continente de origen (2007-2019).

\begin{tabular}{|l|r|r|r|r|r|r|r|r|r|r|r|r|r|}
\hline & $\mathbf{2 0 0 7}$ & $\mathbf{2 0 0 8}$ & $\mathbf{2 0 0 9}$ & $\mathbf{2 0 1 0}$ & $\mathbf{2 0 1 1}$ & $\mathbf{2 0 1 2}$ & $\mathbf{2 0 1 3}$ & $\mathbf{2 0 1 4}$ & $\mathbf{2 0 1 5}$ & $\mathbf{2 0 1 6}$ & $\mathbf{2 0 1 7}$ & $\mathbf{2 0 1 8}$ & $\mathbf{2 0 1 9}$ \\
\hline Europa & $86,7 \%$ & $87,1 \%$ & $83,5 \%$ & $86,1 \%$ & $89,5 \%$ & $89,8 \%$ & $89,0 \%$ & $90,6 \%$ & $90,2 \%$ & $90,3 \%$ & $91,6 \%$ & $89,9 \%$ & $90,6 \%$ \\
\hline América & $5,2 \%$ & $5,2 \%$ & $5,9 \%$ & $5,8 \%$ & $6,7 \%$ & $5,7 \%$ & $5,9 \%$ & $5,1 \%$ & $4,8 \%$ & $6,1 \%$ & $4,0 \%$ & $4,6 \%$ & $5,2 \%$ \\
\hline África & $1,3 \%$ & $1,4 \%$ & $2,0 \%$ & $1,7 \%$ & $1,0 \%$ & $1,4 \%$ & $1,2 \%$ & $1,4 \%$ & $1,2 \%$ & $0,9 \%$ & $1,0 \%$ & $1,0 \%$ & $1,4 \%$ \\
\hline Japón & $0,4 \%$ & $0,3 \%$ & $0,4 \%$ & $0,4 \%$ & $0,3 \%$ & $0,3 \%$ & $0,3 \%$ & $0,3 \%$ & $0,4 \%$ & $0,5 \%$ & $0,2 \%$ & $0,1 \%$ & $0,4 \%$ \\
\hline $\begin{array}{l}\text { Resto del } \\
\text { Mundo }\end{array}$ & $6,4 \%$ & $6,0 \%$ & $8,1 \%$ & $6,1 \%$ & $2,5 \%$ & $2,8 \%$ & $3,7 \%$ & $2,6 \%$ & $3,4 \%$ & $2,2 \%$ & $3,2 \%$ & $4,4 \%$ & $2,4 \%$ \\
\hline
\end{tabular}

Fuente: Elaboración propia a través de los datos de Murcia Turística.

Entre los países europeos destaca la aportación de Reino Unido, que en 2007 aportó un tercio de las recepciones extranjeras en la Región. Los efectos de la crisis económica hacen mella en la cantidad de personas recibidas de nacionalidad británica, ya que se redujo casi a la mitad (37.576 turistas en 2009) durante el último año de la primera década del siglo XXI. Años después, el valor se ha ido recuperando, aunque en los últimos años se ha registrado una caída. Además, es preciso destacar la contribución de otras naciones como Francia, Italia o Alemania, si bien presentan cifras bastante más modestas que el Reino Unido. (Figura 8). 
Figura 8: Evolución del número de turistas que llegan a la R. de Murcia procedentes de los principales países europeos

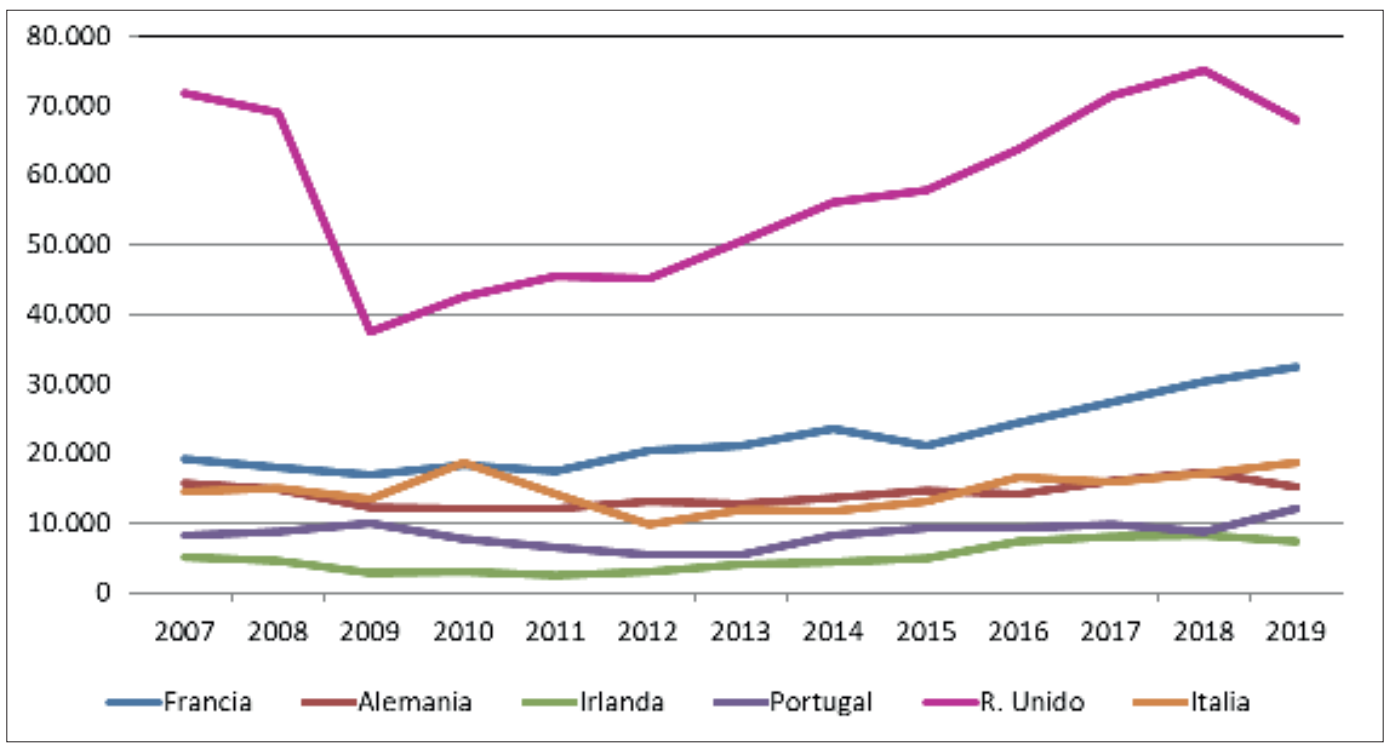

Fuente: Elaboración propia a través de los datos de Murcia Turística.

En una escala de mayor detalle, los datos derivados del origen de los turistas en los municipios del litoral murciano estudiados muestran un comportamiento similar al del total regional. Los viajeros con residencia en España suponen dos tercios del total, acusando una gran caída durante los años en los que el impacto de la crisis fue más patente (Figura 9).

Figura 9: Evolución de los turistas que llegan a las áreas turísticas estudiadas en función de si residen o no en España

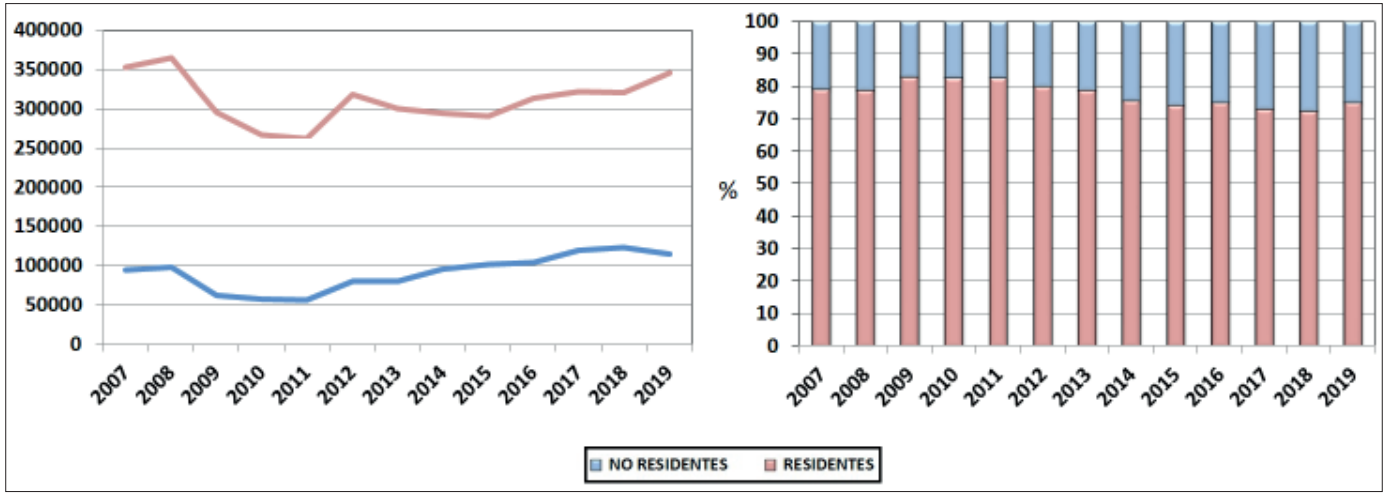

Fuente: Elaboración propia a través de los datos de Murcia Turística.

La evolución de las llegadas de ciudadanos no residentes en España también se vio afectada por la recesión. A pesar de ello, desde el 2011 el peso del turismo extranjero se ha ido incrementando, llegando a suponer en 2018 el 25\% de los desplazamientos totales. Estos ciudadanos no residentes en España viajan principalmente a la vertiente SE del litoral murciano, recalando con mayor asiduidad en los municipios correspondientes al resto del Mar Menor (Figura 10). Las razones que apoyan esta tendencia pueden atribuirse a la mayor proximidad de los aeropuertos que dan servicio a estas áreas (Murcia-San Javier y Alicante). 
Figura 10: Evolución porcentual de la llegada de turistas a las áreas estudiadas en función de si residen o no en España

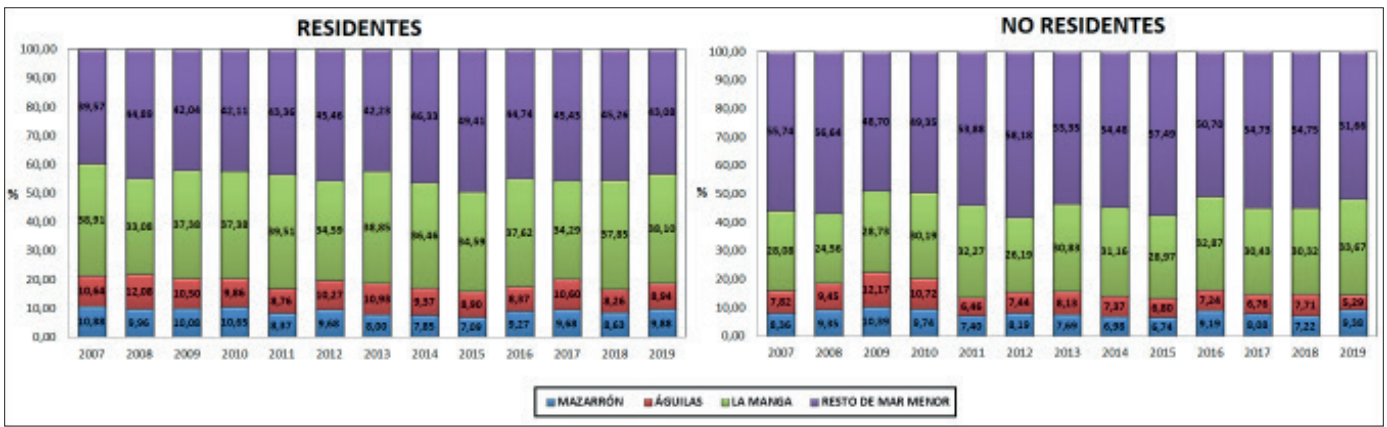

Fuente: Elaboración propia a través de los datos de Murcia Turística.

En lo que respecta a los viajeros nacionales llegados al litoral de la Región de Murcia, las estadísticas muestran un comportamiento similar al del conjunto regional. Así, la Comunidad Valenciana, Andalucía, la Comunidad de Madrid y la propia Región de Murcia constituyen los focos de emisión mayoritaria (casi tres cuartas partes del total) (Figura 11).

Figura 11: Evolución porcentual de los turistas nacionales que llegan a la costa de la R. de Murcia en función de la Comunidad Autónoma de procedencia

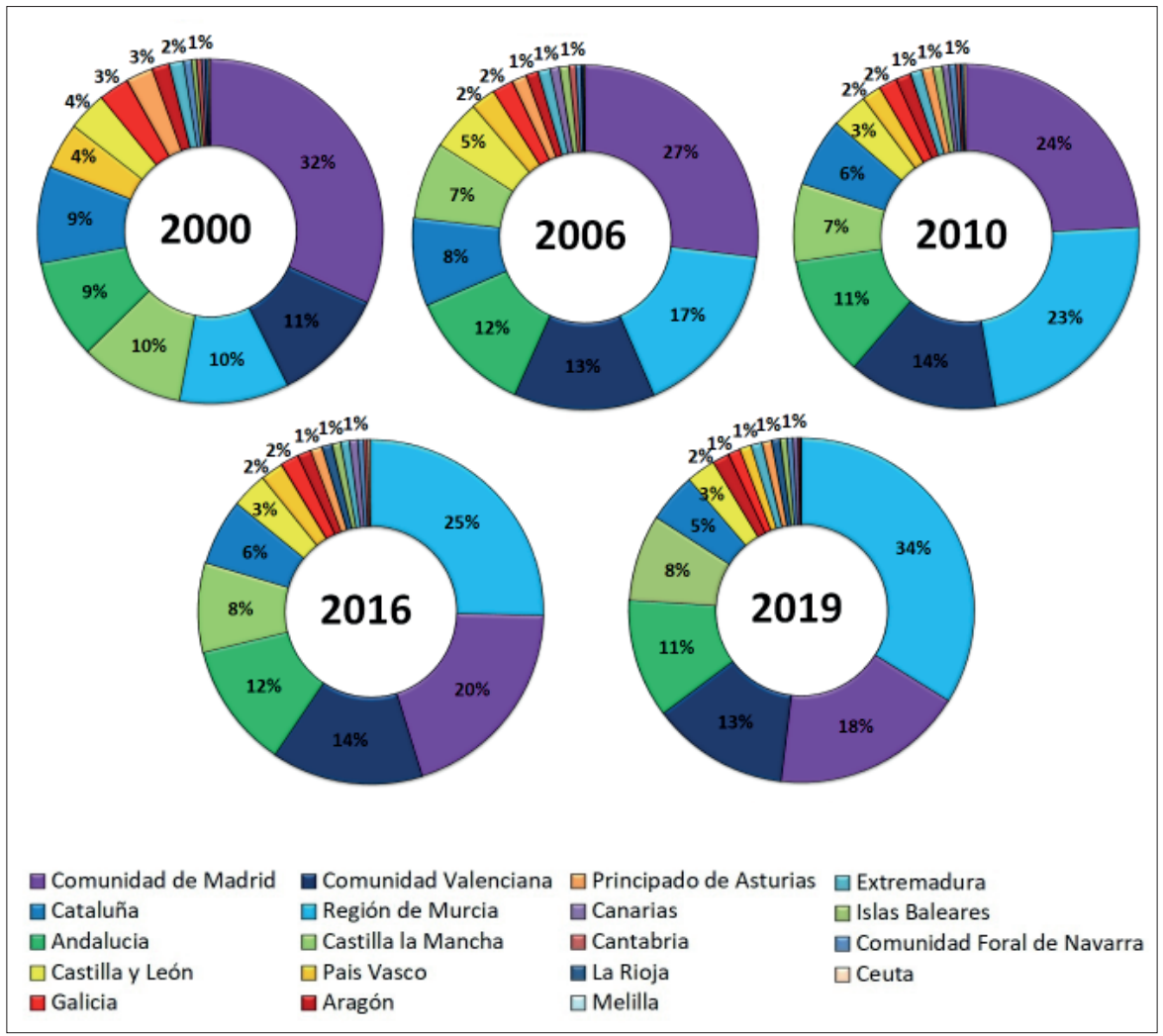

Fuente: Elaboración propia a través de los datos de Murcia Turística. 
La Comunidad de Madrid ha sido la que, tradicionalmente, mayor cantidad de viajeros ha aportado al turismo en la costa de la Región de Murcia. Madrid es el principal origen del masivo peregrinaje de ciudadanos que año tras año escogen el litoral murciano durante los periodos vacacionales. La cuantía de turistas procedentes de esta Comunidad Autónoma ha ido perdiendo importancia con los años, pasando de representar el 32\% en el año 2000, al 17\% en 2019. Esta situación es debida al incremento de turistas procedentes del resto de territorios de relevancia señalados. Cabe resaltar la influencia que la población de la propia región ha ido obteniendo durante los últimos años (24\% en 2019). Esto se puede atribuir, entre otros factores, a la situación económica mencionada y al abaratamiento de los costes de logística que supone el desplazamiento. Además, conviene indicar que, debido a su proximidad geográfica, Andalucía y la Comunidad Valenciana han mantenido históricamente una presencia considerable.

Por otro lado, la procedencia de los turistas extranjeros que llegan a los municipios litorales muestra un patrón muy parecido al regional (Tabla 6). Los ciudadanos europeos son, con diferencia, los que más viajan a la costa murciana, representando cada año en torno al $90 \%$ de los viajeros totales. Por su parte, la significación de los americanos ronda cada año entre el 5 y el 6\%. Esto viene motivado, tal y como se ha comentado en líneas anteriores para el conjunto regional, a las visitas que realizan los familiares de los inmigrantes sudamericanos afincados en la Región de Murcia.

Tabla 6: Reparto porcentual de los turistas extranjeros en la costa de la R. de Murcia en función del continente de origen (2007-2019).

\begin{tabular}{|c|c|c|c|c|c|c|c|c|c|c|c|c|c|}
\hline & 2007 & 2008 & 2009 & 2010 & 2011 & 2012 & 2013 & 2014 & 2015 & 2016 & 2017 & 2018 & 2019 \\
\hline Europa & $86,7 \%$ & $87,1 \%$ & $83,5 \%$ & $86,1 \%$ & $89,5 \%$ & $89,8 \%$ & $89,0 \%$ & $90,6 \%$ & $90,2 \%$ & $90,3 \%$ & $91,6 \%$ & $89,9 \%$ & $90,6 \%$ \\
\hline América & $5,2 \%$ & $5,2 \%$ & $5,9 \%$ & $5,8 \%$ & $6,7 \%$ & $5,7 \%$ & $5,9 \%$ & $5,1 \%$ & $4,8 \%$ & $6,1 \%$ & $4,0 \%$ & $4,6 \%$ & $5,2 \%$ \\
\hline África & $1,3 \%$ & $1,4 \%$ & $2,0 \%$ & $1,7 \%$ & $1,0 \%$ & $1,4 \%$ & $1,2 \%$ & $1,4 \%$ & $1,2 \%$ & $0,9 \%$ & $1,0 \%$ & $1,0 \%$ & $1,4 \%$ \\
\hline Japón ${ }^{2}$ & $0,4 \%$ & $0,3 \%$ & $0,4 \%$ & $0,4 \%$ & $0,3 \%$ & $0,3 \%$ & $0,3 \%$ & $0,3 \%$ & $0,4 \%$ & $0,5 \%$ & $0,2 \%$ & $0,1 \%$ & $0,4 \%$ \\
\hline $\begin{array}{l}\text { Resto del } \\
\text { Mundo }\end{array}$ & $6,4 \%$ & $6,0 \%$ & $8,1 \%$ & $6,1 \%$ & $2,5 \%$ & $2,8 \%$ & $3,7 \%$ & $2,6 \%$ & $3,4 \%$ & $2,2 \%$ & $3,2 \%$ & $4,4 \%$ & $2,4 \%$ \\
\hline
\end{tabular}

Fuente: Elaboración propia a través de los datos de Murcia Turística.

$\mathrm{Al}$ analizar las llegadas de los turistas europeos en función del país de procedencia se observa un comportamiento un tanto similar al del conjunto regional (Figura 12). No obstante, las diferencias entre el Reino Unido y el resto de estados son mucho más acusadas, ya que por ejemplo en el año 2007 casi la mitad de los viajeros extranjeros fueron británicos (49,99\%). A día de hoy, pese liderar la estadística de forma amplia, su significación ha bajado hasta el $40 \%$. Es decir, el número de turistas de otros países que llega a la costa de la Región de Murcia va aumentando de forma paulatina año tras año.

Figura 12: Evolución del número de turistas que llegan al litoral de la R. de Murcia procedentes de los principales países europeos

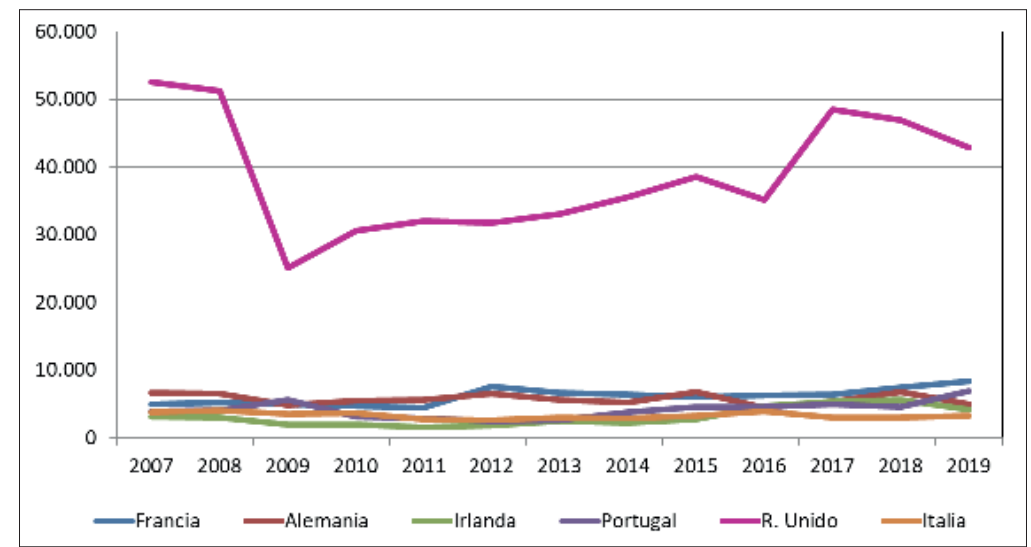

Fuente: Elaboración propia a través de los datos de Murcia Turística. 


\subsubsection{Análisis de las pernoctaciones}

La evolución de las pernoctaciones en la Región de Murcia se ha desarrollado de forma prácticamente similar a la recepción de viajeros, lo que se puede atribuir a la relación directa que poseen ambas variables. La brecha presente entre las pernoctaciones realizadas en la totalidad de la superficie regional y los municipios litorales analizados es menos abultada que en lo que a recepción de viajeros se refiere. Tal es la relevancia pernoctacional de la franja litoral, que las cuatro áreas turísticas examinadas hospedan a la mitad de viajeros que llegan a la Región de Murcia (Figura 13).

Figura 13: Evolución de las pernoctaciones realizadas en la R. de Murcia y su litoral.

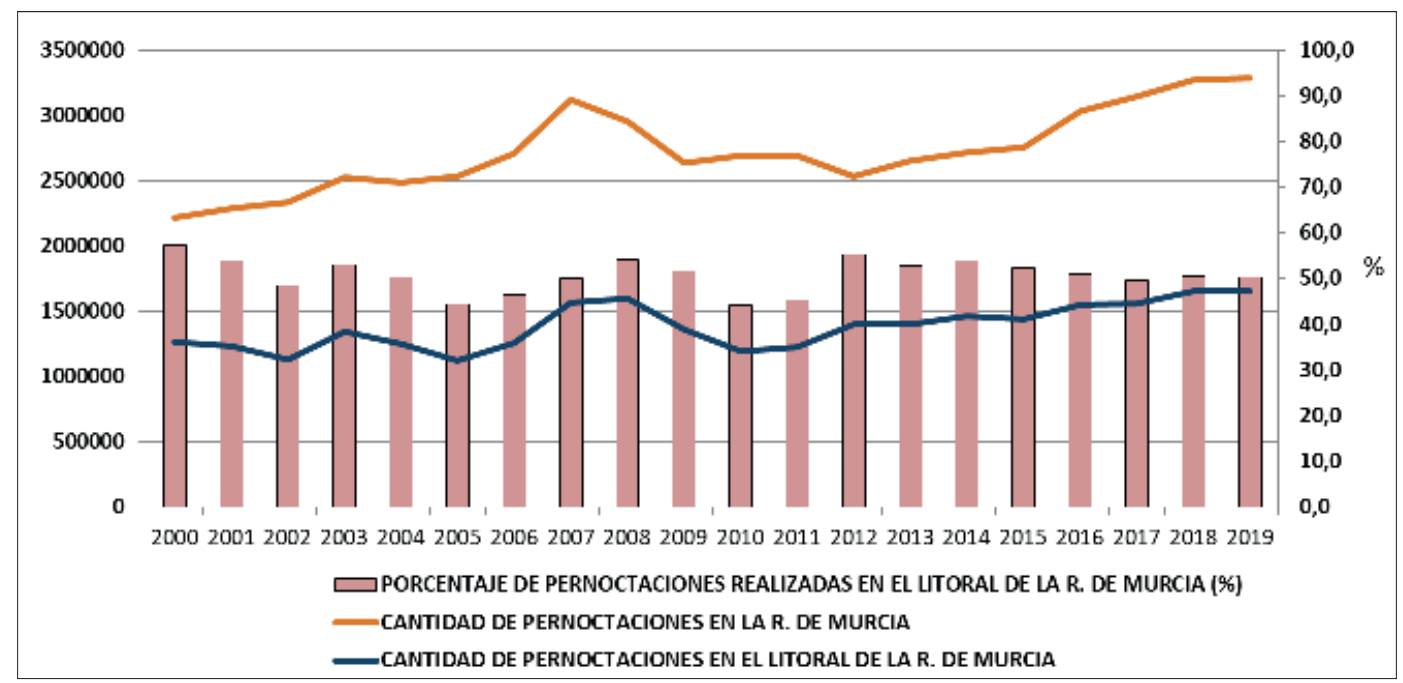

Fuente: Elaboración propia a través de los datos de Murcia Turística.

El hecho fundamental que explica el elevado peso de las pernoctaciones realizadas en la costa murciana sobre el total regional se debe a que en torno al $90 \%$ de todos los establecimientos turísticos regionales y el 70\% de las plazas hoteleras se concentran en el litoral. La mayor parte de las pernoctaciones regionales son efectuadas por población residente en España (cerca del 80\%), valor que está descendiendo durante los últimos años en favor de los hospedajes de población residente fuera de las fronteras nacionales (Figura 14).

Figura 14: Evolución de las pernoctaciones realizadas en la $R$. de Murcia en función de si residen o no en España

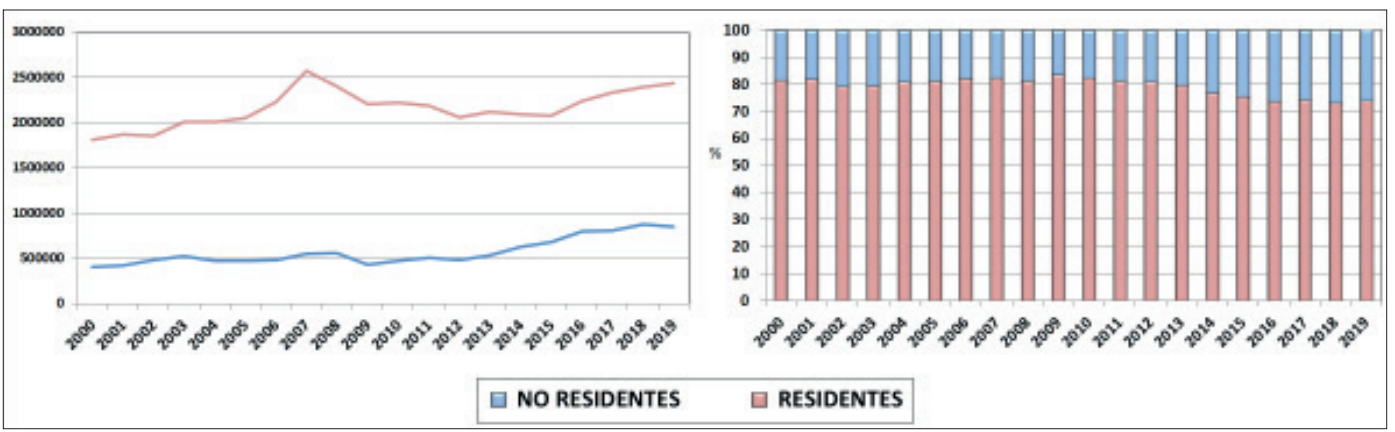

Fuente: Elaboración propia a través de los datos de Murcia Turística.

En cuanto a las pernoctaciones realizadas en los municipios analizados, cabe resaltar que la práctica totalidad de las mismas se efectúan en el área turística regional por excelencia, La Manga (Figura 
15). Por su parte, el resto del Mar Menor, a pesar de acoger casi la mitad de los establecimientos y un tercio de las plazas turísticas ofertadas en la superficie autonómica, mantiene un valor de pernoctación inferior al de la restinga (La Manga).

\section{Figura 15: Evolución porcentual de las pernoctaciones en áreas turísticas estudiadas}

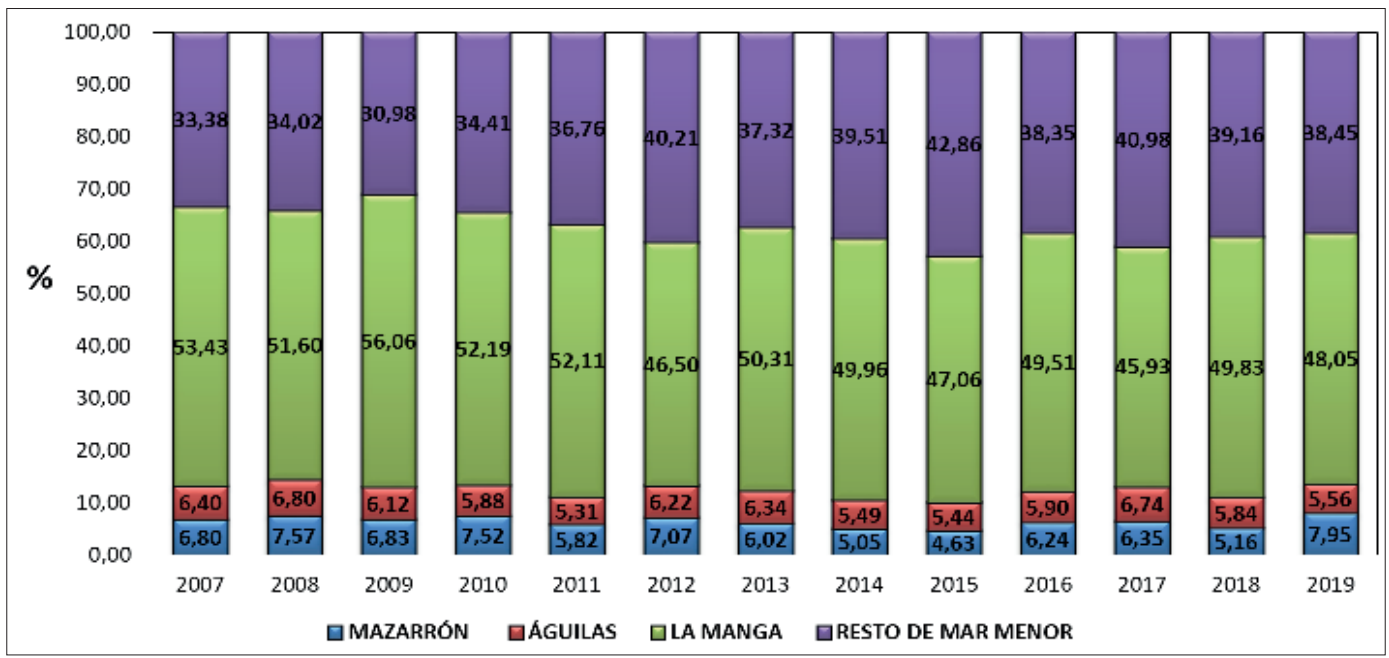

Fuente: Elaboración propia a través de los datos de Murcia Turística.

La escasez de infraestructuras turísticas que ofertan los municipios del SW regional provoca que las pernoctaciones realizadas en Águilas y Mazarrón se sitúen en torno a la décima parte del total (13,5\% en 2019). Ambas áreas son las menos demandadas por los turistas, tanto residentes como no residentes, registrando los datos en función del origen del turista ciertas discordancias en las delimitaciones costeras situadas al SE regional (Figura 16).

Figura 16: Evolución porcentual de las pernoctaciones en las áreas estudiadas en función de si residen o no en España

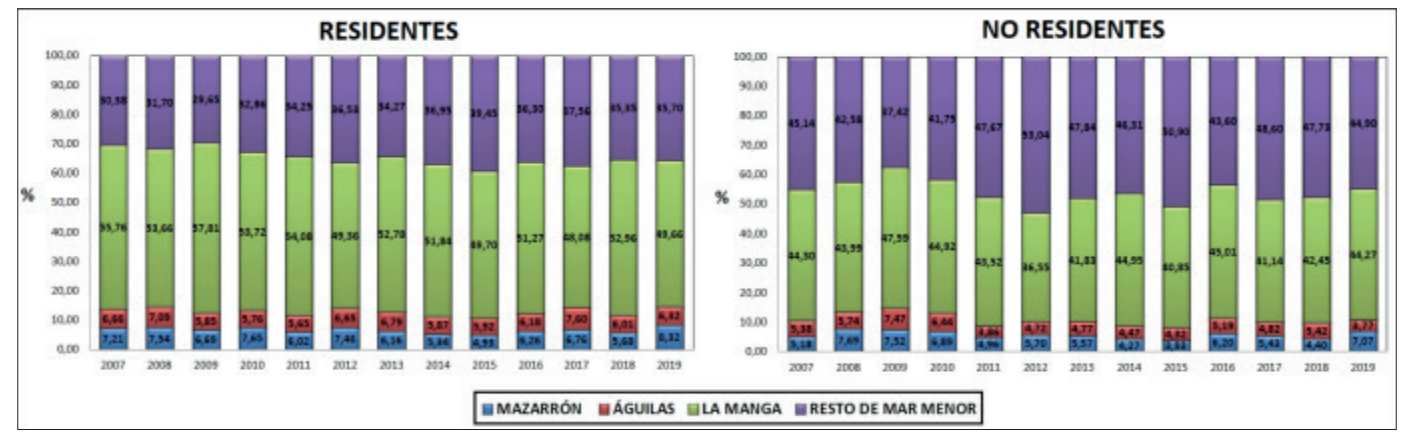

Fuente: Elaboración propia a través de los datos de Murcia Turística.

En cierto modo, concurre una cierta predisposición que indica que los turistas residentes en España tienden a pernoctar en La Manga, en mayor medida que los que lo hacen procedentes del extranjero, optando por alojarse estos últimos en establecimientos localizados en el resto del Mar Menor. Las razones pueden emanar de diversos hechos, como la ya mencionada predilección de los extranjeros por la Costa Blanca, la proximidad al aeropuerto de Alicante o la magnífica consideración turística que La Manga posee entre los turistas nacionales. 


\subsubsection{Establecimientos y plazas hoteleras}

En una investigación de estas características, y con el fin de alcanzar un mayor detalle en el análisis del turismo, es preciso averiguar el número de establecimientos turísticos y las plazas hoteleras existentes.

\subsubsection{Establecimientos}

La franja litoral reúne la mayor parte de las instalaciones turísticas regionales, acogiendo las cuatro áreas estudiadas el 77,1\% (2.023) de las mismas. La ubicación de los establecimientos turísticos es el indicador que refleja con mayor claridad el patente contraste de desarrollo turístico experimentado entre las diferentes áreas. De tal forma que las ubicadas en el entorno del Mar Menor aglutinan gran parte de estos establecimientos (65,8\% de los regionales y cerca del $85,5 \%$ de los presentes en los municipios analizados). Ahora bien, a causa del marcado contraste de superficies entre ambas áreas, el número de alojamientos turísticos presenta un balance un tanto dispar, localizando en el resto del Mar Menor un mayor número de infraestructuras (Tabla 7).

Tabla 7: Cantidad de establecimientos turísticos (2019)

\begin{tabular}{|c|c|c|c|c|c|c|}
\hline \multicolumn{7}{|c|}{ ESTABLECIMIENTOS } \\
\hline & Apartamentos & Hoteles & Pensiones & Total & $\begin{array}{c}\text { \% Con respecto al } \\
\text { total regional }\end{array}$ & $\begin{array}{c}\text { \% Con respecto al } \\
\text { litoral estudiado }\end{array}$ \\
\hline $\begin{array}{c}\text { Total región } \\
\text { de murcia }\end{array}$ & 2408 & 160 & 56 & 2624 & 100 & - \\
\hline $\begin{array}{c}\text { Total litoral } \\
\text { estudiado }\end{array}$ & 1945 & 54 & 24 & 2023 & 77,1 & 100 \\
\hline Águilas & 97 & 6 & 7 & 110 & 4,2 & 5,4 \\
\hline Mazarrón & 167 & 11 & 7 & 185 & 7,1 & 9,1 \\
\hline La Manga & 746 & 10 & 0 & 756 & 28,8 & 47,5 \\
\hline $\begin{array}{c}\text { Resto del Mar } \\
\text { Menor }\end{array}$ & 935 & 27 & 10 & 972 & 37,0 & 48,0 \\
\hline
\end{tabular}

Fuente: Centro Regional de Estadística de la Región de Murcia (CREM).

La escasez de equipamientos constituye el principal síntoma del estancamiento turístico en Mazarrón y Águilas, municipios que registran 185 y 110 establecimientos con capacidad de hospedaje, respectivamente. $\mathrm{Al}$ igual que en el resto del territorio, el apartamento es la tipología de establecimiento más numerosa, contabilizando a escala regional más de dos millares y medio de los mismos.

El 88\% de los apartamentos se sitúan de forma aparentemente repartida entre las áreas costeras mencionadas. La mitad de los 54 hoteles construidos en estos espacios turísticos se concentran en el resto del Mar Menor, repartiéndose los demás de forma más equitativa entre las tres áreas restantes (Figura 17).

Figura 17: Reparto porcentual de equipamientos turísticos en las áreas estudiadas según tipología (2019)

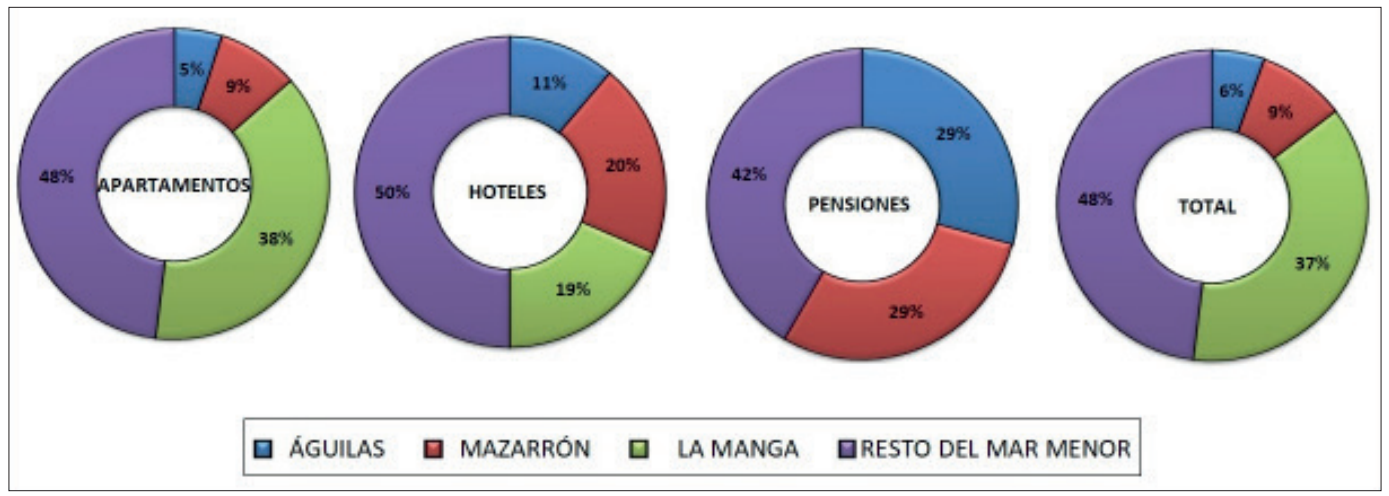

Fuente: Elaboración propia a través de los datos del CREM. 
La categoría de estas instalaciones es variada en función del área en el que se localiza, observando un reparto prácticamente similar de hoteles de 4, 3 y 2 estrellas en el área de mayor pujanza turística (resto de Mar Menor), un predominio de hoteles de 3 y 2 estrellas en Águilas y Mazarrón y una notoriedad de hoteles de 4 estrellas en La Manga, espacio en el que no se localizan hoteles de 2 y 1 estrella ni pensiones (Figura 18).

\section{Figura 18: Reparto porcentual de la categoría de infraestructuras hoteleras y pensiones en las áreas estudiadas (2019)}
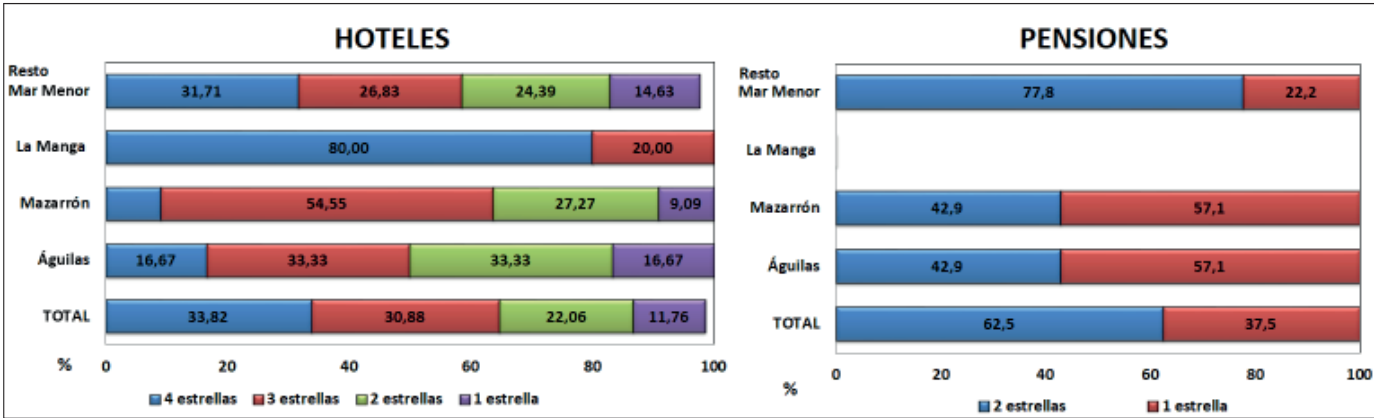

Fuente: Elaboración propia a través de los datos del CREM.

En el ámbito de estudio sólo se localiza un hotel de 5 estrellas, La Manga Club Resort, ubicado en el término municipal de Cartagena, concretamente en las inmediaciones del Parque Regional de Calblanque y a escasos $5 \mathrm{~km}$ del Mar Menor. Interesa advertir que esta instalación se localiza en el entorno de un campo de golf, por lo que en cierta medida está orientado al turismo deportivo.

En cuanto a las instalaciones hospederas de menor calidad (pensiones), el área objeto de estudio alberga 32 de las 55 que se localizan en la totalidad del territorio regional. Estas se reparten entre las delimitaciones turísticas de resto del Mar Menor (18) y Mazarrón y Águilas con 7 en cada municipio. Entre las categorías de pensiones, de forma global, se registra un balance relativamente equilibrado, localizándose las de mayor estatus en la demarcación correspondiente al resto del Mar Menor.

\subsubsection{Plazas hoteleras}

Con la finalidad de obtener un análisis de mayor detalle, es preciso estudiar la cantidad de plazas hoteleras que poseen los establecimientos, constituyendo un indicador fundamental para contrastar y conocer el desarrollo turístico experimentado por cada área (Tabla 8).

Tabla 8: Cantidad de plazas turísticas (2019)

\begin{tabular}{|l|c|c|c|c|c|c|}
\hline & Apartamentos & Hoteles & Pensiones & Total & $\begin{array}{c}\text { \% Con } \\
\text { respecto al } \\
\text { total regional }\end{array}$ & $\begin{array}{c}\text { \% Con } \\
\text { respecto al } \\
\text { litoral estudiado }\end{array}$ \\
\hline $\begin{array}{l}\text { Total región } \\
\text { de murcia }\end{array}$ & 10035 & 19428 & 1341 & 30804 & 100 & - \\
\hline $\begin{array}{l}\text { Total litoral } \\
\text { estudiado }\end{array}$ & 8230 & 10014 & 689 & 18933 & 61,5 & 100 \\
\hline Águilas & 471 & 588 & 176 & 1235 & 4 & 6,5 \\
\hline Mazarrón & 872 & 858 & 132 & 1862 & 6,1 & 9,9 \\
\hline La Manga & 3412 & 4486 & 0 & 7898 & 25,6 & 41,7 \\
\hline $\begin{array}{l}\text { Resto del } \\
\text { Mar Menor }\end{array}$ & 3475 & 4082 & 381 & 7938 & 25,8 & 41,9 \\
\hline
\end{tabular}

Fuente: Centro Regional de Estadística de la Región de Murcia (CREM). 
La representación de plazas turísticas registradas en las áreas observadas (61,5\%) presenta menor peso en el contingente regional que los establecimientos que albergan las mismas, lo que indica la antigüedad y baja capacidad de estas. Al igual que en el caso de los establecimientos, la mayor parte de las 18.933 plazas se reparten entre las dos áreas turísticas generadas en torno al Mar Menor (83,6\%). A pesar de que ambas muestran unos valores similares, interesa advertir que en La Manga existe una menor cantidad de establecimientos pero contabilizan un mayor número de plazas. Este indicador no hace más que reforzar el hecho de que La Manga registra el parque de equipamiento turístico de menor antigüedad y mayor calidad ( $80 \%$ de sus hoteles son de 4 estrellas) de las áreas litorales, capaz de alojar a casi el 30\% de los viajeros que llegan a la región.

La mayor parte de estas plazas se localizan en hoteles, equipamientos que por su orientación meramente turística (a diferencia de los apartamentos) son capaces de optimizar el espacio y ofrecer mayor número de localidades turísticas a ocupar por los viajeros (Figura 19). La Manga es el área que acoge la mayor parte de plazas en hoteles (4.486), constituyendo estas el grueso $(56,79 \%)$ de su oferta hospedera. De la misma forma, el 44,80\% de las plazas ofertadas por todos los hoteles construidos en el litoral murciano se localizan en La Manga, cifra algo superior a la capacidad de acogida turística que representa el resto del Mar Menor (40,76\%).

\section{Figura 19: Reparto porcentual de las plazas turísticas en las áreas estudiadas según tipología (2019)}

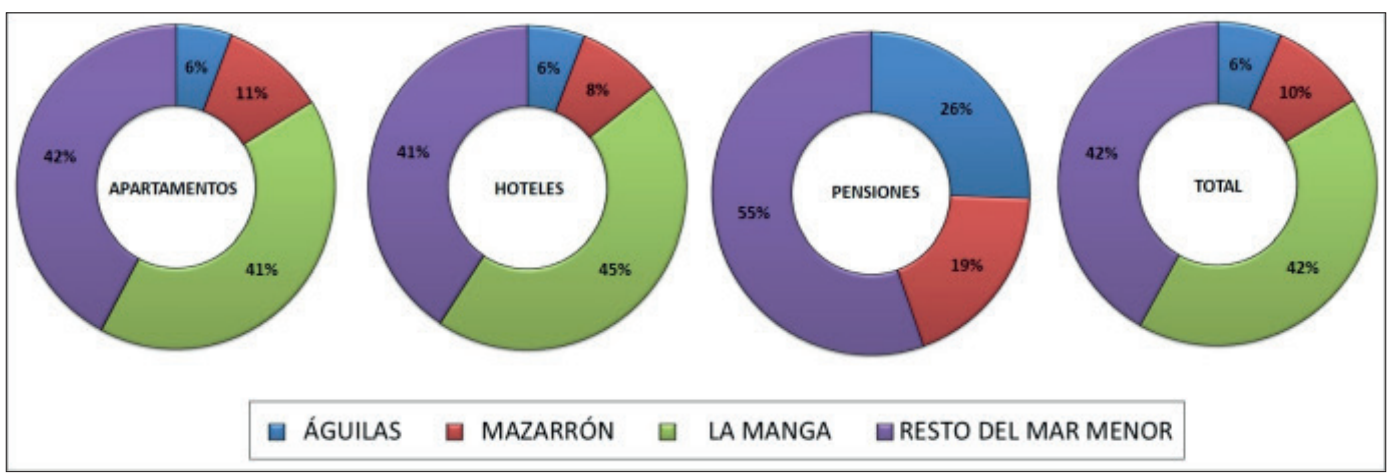

Fuente: Elaboración propia a través de los datos del CREM.

El caso de las plazas ofertadas en apartamentos es similar, repartiéndose las más de siete mil quinientas disponibles entre estos dos ámbitos. Las contabilizadas en Mazarrón (872) y Águilas (471) apenas superan el 16\% del total. En lo que respecta a las pensiones, ambos municipios cobran cierta relevancia, ya que el desarrollo del turismo es menor que en la zona del Mar Menor debido a que la pesca y la agricultura siguen siendo sectores clave. Así, su oferta turística se basa en infraestructuras de menor calidad. Entre Mazarrón y Águilas concentran casi el 45\% de las plazas en pensiones, mientras que en La Manga no hay pensiones y las restantes se localizan en las localidades del resto del Mar Menor (55\%).

\section{Conclusiones}

Como se ha constatado, la cantidad de viajeros que escogen la Región de Murcia como destino vacacional es netamente inferior al del resto de Comunidades Autónomas y provincias analizadas. Este hecho se refleja en el escaso peso que el sector turístico murciano posee en el cómputo nacional. Además, esta actividad manifiesta diversas anomalías y disparidades dentro del propio territorio regional. La afluencia de viajeros en cada uno de los focos de recepción turística permanece asociado, directamente, a la cantidad y calidad de los establecimientos que dan servicio. En este sentido, se puede apreciar un dilatado contraste entre la dinamicidad turística que presenta, por un lado, el litoral con respecto al resto de la superficie autonómica, y por otro, la brecha existente entre los diferentes espacios costeros. 
Esta situación permanece condicionada a que, prácticamente, 9 de cada 10 establecimientos turísticos construidos en esta región se emplazan en el litoral (70\% de las plazas hoteleras).

La mayor parte de estos establecimientos y plazas hoteleras ubicadas en la franja costera se localizan en La Manga y los entornos del Mar Menor (cerca del 86\%). Se trata de los dos escenarios de ocio y recreación de mayor relevancia regional, espacios pioneros en el desarrollo turístico de sol y playa a nivel nacional e internacional.

Por su parte, el desarrollo turístico de Águilas y Mazarrón permanece ceñido al devenir de otros sectores económicos (agricultura y pesca) de mayor tradición. Ambos municipios apenas registran el $11 \%$ de los establecimientos turísticos regionales (14\% de los ubicados en el litoral), ligando la mayor parte de su turismo a las segundas residencias.

En cuanto al origen de los turistas se refiere, 8 de cada 10 poseen nacionalidad española, de los cuales el $25 \%$ pertenecen a la propia región. Con la excepción de Málaga y Baleares (espacios con predominio de turistas extranjeros), el resto de Comunidades Autónomas examinadas muestran mayor homogeneidad que Murcia en el reparto de la recepción de viajeros según nacionalidad. Entre los turistas no residentes en España, sobresale la tradicional presencia de individuos procedentes del Reino Unido. Este territorio llegó a aportar la mitad de las personas extranjeras que visitaron la región por motivos turísticos (hasta 2007), cifra que se ha reducido durante los últimos años a causa de la recesión económica. Además, es necesario advertir una posible disminución de los turistas británicos a causa del Brexit. Así, según informes del Banco de España el impacto económico para la economía española será moderado. Sin embargo, el turismo es uno de los sectores que más puede verse afectado (Correas y Del Olmo, 2019), por lo que en la Región de Murcia podría disminuir en los próximos años el número de viajeros británicos.

Es necesario advertir que, durante los últimos años, las localidades de Águilas y Mazarrón han impulsado la mejora de su oferta hotelera. A pesar de ello, no parece que la tesitura actual vaya a cambiar, por lo que el conjunto del Mar Menor seguirá siendo el espacio turístico por excelencia de la región. Tampoco parece que vaya a reducirse la brecha existente entre la recepción de turistas y pernoctaciones de los mismos en la Región de Murcia con respecto a las Comunidades Autónomas y provincias inmediatas analizadas, ya que, tal y como evidencian los datos, si sigue la tónica actual se acrecentarán.

Finalmente, parece oportuno mencionar la crisis sanitaria de 2020 fruto de la pandemia de la COVID-19. No cabe duda de que el sector turístico es uno de los más afectados. Tal y como afirman Gössling et al., (2020), la magnitud de la pandemia se puede considerar como una oportunidad para reconsiderar una transformación del turismo alineado con los Objetivos de Desarrollo Sostenible (ODS). En este sentido existen diversas cuestiones por resolver como la existencia de un control más estricto de las fronteras, el papel del turismo nacional en la recuperación y cómo evolucionarán los destinos turísticos. Como no puede ser de otro modo, la Región de Murcia no queda ajena a esta tesitura, por lo que la planificación del turismo jugará un papel decisivo en el desarrollo del territorio.

\section{Bibliografia}

Aledo, A. 2016. Turismo residencial y vulnerabilidad en el interior del Levante español. In J. Gascón \& E. Cañada (Eds.), Turismo residencial y gentrificación rural (37-60). El Sauzal (Tenerife), España: PASOS, RTPC \& Foro de Turismo Responsable.

Andrés, J.L. 2004. Incertidumbres en el espacio agrícola y proceso urbanizador "resort" en la Región de Murcia. Cuadernos de Turismo, 14, 7-65.

Artal, A., García, A. y Navarro, J.M. 2010. Factores determinantes de la duración de la estancia turística en un destino de sol y playa: El caso de la Región de Murcia. Cuadernos de Economía, 91(33), 43-66.

Blázquez, M. y Yrigoy, I. 2016. La planificación del turismo en áreas litorales en España. En M. Simancas (Coord.), La planificación y gestión territorial del turismo (pp. 175-203). Madrid, España: Síntesis.

Butler, R.W. 1980. The concept of a tourist area cycle of evolution: Implications for management of resources. The Canadian Geographer, XXIV(I), 5-12.

Cànoves, G., Garay, Ll., Duro, J.A. 2012. Turismo rural en España: Avances y retrocesos en los últimos veinte años. Papers de Turisme, 51, 7-21.

Coll, M.à. Y Seguí, M. 2014. El papel del clima en la estacionalidad turística y la configuración de productos turísticos emergentes. el caso de Mallorca. Cuadernos de turismo, 33, 15-30. 
Correas, B. y del Olmo, F. (2019). Brexit: Panorámica actual e influencia sobre el turismo en España. Documentos de trabajo del IAES (Instituto Universitario de Análisis Económico y Social, Universidad de Alcalá), 6, 1-37.

Daher, A. (2013). El sector inmobiliario y las crisis económicas. Revista de estudios urbanos y regionales, 39(118), 47-76.

Domínguez, R. (2002). La riqueza de las regiones. Las desigualdades regionales en España 1700-2000. Madrid: Alianza Editorial, 403 pp.

Espejo, C. (2011). Innovación para la competitividad turística en la Manga del Mar Menor (Murcia). Cuadernos de Turismo, 27, 321-339.

Fernández, D. (2016). La crisis económica española: Una gran operación especulativa con graves consecuencias. Estudios Internacionales, 48 (183), 119-151.

Giménez, R., García, R. y Serrano, J.M. (2018a). Caracterización del mercado emisor internacional de viajeros españoles. Gran tour, 17, 3-34.

Giménez, R., García, R., Serrano, J.M. y Pulido, M. (2018b). Peri-Urban Dynamics in Murcia Region (SE Spain): The Successful Case of the Altorreal Complex. Urban Science, 2, 1-11.

Gössling, S., Scott, D. y Hall, M. (2020). Pandemics, tourism and global change: a rapid assessment of COVID-19. Journal of Sustainable Tourism. DOI: 10.1080/09669582.2020.1758708.

Goulding, P.J., Baum, T.G. y Morrison, A.J. (2004). Seasonal trading and lifestyle motivatión: Experiences of small tourism businesses in Scotland. Journal of Quality Assurance in Hospitality \& Tourism, 5, 209-238.

Heitmann, S. (2011). Tourist behaviour and tourism motivation. En P. Robinson, S. Heitmann, y P. Dieke (Eds.), Research themes for tourism. Oxford, Reino Unido: CABI Publishing.

Huete, R. (2008). Tendencias del turismo residencial: el caso del Mediterráneo español. El Periplo Sustentable, 14, 65-87.

Moreno, A. (2007). Historia del turismo en España en el siglo XX. Madrid, España: Síntesis.

Pack, S.D. (2009). La invasion pacífica. Los turistas y la España de Franco. Madrid, España: Turner.

Pontes, M.A., García, R., Janoschka, M. y Moreno, D. (2018). Breves consideraciones sobre la influencia del modelo turístico español en Brasil. En T. Mazón (Ed.), Turismo residencial. Nuevos estilos de vida: de turistas a residentes (pp. 263-274). Alicante, España: Universidad de Alicante.

Sebit, J., Wolff, M., Breckwoldt, A., y Jiddawi, N. (2016). Have the fishing communities of Zanzibar Island benefited from increasing tourism development?. Journal of Development and Agricultural Economics, 8 (5), 95-107.

Serrano, J.M. (1993). Dinámica de crecimiento y difusión espacial de las viviendas secundarias en España en los inicios de los años 90. Bilbao: Banco Bilbao - Vizcaya, 45-64.

Serrano, J.M. (2001). Los transportes en la Región de Murcia. Accesibilidad y desenclave dentro del Sureste Español. Murcia: Fundación Centro de Estudios Históricos e Investigaciones Locales, 318 pp.

Serrano, J.M. (2007). El turismo residencial en la Región de Murcia frente a los nuevos retos. Cuadernos de Turismo, 19, 189-216.

Serrano, J.M. 2016. Lorca, municipio y ciudad; Accesibilidad y desenclave. En R. García (Ed.), Lorca: Ciudad Histórica del Mediterráneo (pp. 73-118). Murcia, España: Fundación Séneca: Agencia de Ciencia y Tecnología de la Región de Murcia.

Serrano, J.M. y Calmés, R. 1998. L'Espagne. Du sous-devéloppement au developpement. París: L' Harmattan, 302 pp.

Serrano, J.M., Espejo, C. y García, R. 2016. Accesibilidad aérea en la Región de Murica: Una encrucijada compleja desde una perspectiva turística. Papers de Turisme, 59, 62-85.

Simancas, M. y Ledesma, O. 2016. La planificación territorial de la política de renovación de las áreas turísticas maduras. Planes de Renovación, Mejora e Incremento de la Competitividad de Canarias. PASOS: Revista de Turismo y Patrimonio Cultural, 14 (2), 335-352.

Torres, E., Ramírez, R. y Rodríguez, B. 2014. La crisis económica en el sector turístico. Un análisis de sus efectos en la Costa del Sol. Revista de análisis turístico, 18, 11-18.

UNWTO. 2020. International tourist arrivals could fall by 20-30\% in 2020. Recuperado de https:// www. unwto.org/news/international-tourism-arrivals-could-fall-in-2020

Vera, J.F. 1994. El modelo turístico del mediterráneo español: agotamiento y herramientas de reestructuración. Papers de turisme, 11, 7-32.

Vera, J.F. y Baños, C.J. 2010. Renovación y reestructuración de los destinos turísticos consolidados del litoral: Las prácticas recreativas en la evolución del espacio turístico. Boletín de la Asociación de Geógrafos Españoles, 53, 329-353. 
Vera, J.F. y Baños, C.J. 2016. La dimensión territorial del turismo. Los objetos de la ordenación territorial de áreas turísticas: la definición del sistema turístico. En M. Simancas (Coord.), La planificación y gestión territorial del turismo (pp. 51-83). Madrid, España: Síntesis.

\section{Notas}

1 Nota aclaratoria: Las estadísticas de Murcia Turística solo especifican a Japón entre los países asiáticos. Es decir, el resto de viajeros procedentes de Asia y Oceanía quedan englobados en Resto del Mundo.

2 Nota aclaratoria: Las estadísticas de Murcia Turística solo especifican a Japón entre los países asiáticos. Es decir, el resto de viajeros procedentes de Asia y Oceanía quedan englobados en Resto del Mundo. 